\title{
Influence of Dietary Ingredients on Lean Body Percent, Uremic Toxin Concentrations, and Kidney Function in Senior-Adult Cats
}

\author{
Jean A. Hall 1,*, Matthew I. Jackson ${ }^{2}$, Giosi Farace ${ }^{3}$, Maha Yerramilli ${ }^{3}$ and Dennis E. Jewell ${ }^{2}$ \\ 1 Department of Biomedical Sciences, College of Veterinary Medicine, Oregon State University, Corvallis, \\ Oregon, OR 97333-4802, USA \\ 2 Pet Nutrition Center, Hill's Pet Nutrition, Topeka, Kansas, KS 66617-1587, USA; \\ matthew_jackson@hillspet.com (M.I.J.); jewelldj55@gmail.com (D.E.J.) \\ 3 IDEXX Laboratories, One IDEXX Drive, Westbrook, ME 04092, USA; giosi-farace@idexx.com (G.F.); \\ maha-yerramilli@idexx.com (M.Y.) \\ * Correspondence: Jean.Hall@oregonstate.edu
}

Received: 19 August 2019; Accepted: 17 October 2019; Published: 19 October 2019

\begin{abstract}
The goal of this study was to determine if modification of currently available maintenance foods with alternative ingredients, botanicals (fruit and vegetables), and increased amounts of functional lipids (fish oil) would delay the age-associated decline in glomerular filtration rate (GFR) and lean body mass (LBM) in senior-adult cats. Forty-four healthy cats (mean age, 12.2 years; range 10.7 to 14.0 years) were fed one of three foods ( $n=14$ or 15 per group) for six months: control food with $32.6 \%$ protein (as fed), or control food supplemented with increasing amounts of functional food bioactives: fish oil, fruit and vegetables, different protein sources, and $<32.0 \%$ protein [functional foods one (FF1) and two (FF2)]. Senior-adult cats were compared before and after the feeding trial with 20 young-adult cats (mean age, 3.5 years; range 2.1 to 4.9 years). Compared with younger cats, older cats had decreased lean-body percent and serum albumin concentrations. Feeding FF1 and FF2 for six months increased lean-body percent, maintained serum albumin concentrations, increased GFR, decreased serum symmetric dimethylarginine (SDMA) concentrations, and decreased concentrations of the uremic toxin 3-indoxyl sulfate. These dietary changes may assist in offsetting sarcopenia and the chronic inflammation associated with aging in senior-adult cats.
\end{abstract}

Keywords: cats; circulating metabolomes; glomerular filtration rate; lean body mass; renal biomarkers

\section{Introduction}

Similar to humans, aging in cats is associated with sarcopenia [1]. We have previously shown in cats that lean body mass (LBM), glomerular filtration rate (GFR), and serum creatinine (Cr) concentrations decrease with increasing age. Symmetric dimethylarginine (SDMA) concentrations increase with increasing age, indicating a benefit of using serum SDMA versus serum $\mathrm{Cr}$ to assess renal function in older cats [1]. Using serum SDMA concentrations, it is now possible to identify cats with early stages of chronic kidney disease (CKD) before azotemia develops [2]. In humans, no reliable interventions currently exist to prevent CKD-induced muscle wasting [3]. The decline in renal function noted in aging human populations may be associated with increased oxidative stress and inflammation [4]. Our goal was to use a healthy senior-adult cat model to investigate the effects of feeding maintenance food supplemented with functional food bioactives on LBM, GFR, and biomarkers and metabolites associated with aging. We have previously called such foods renal protective foods (RPF) [5]. Lessons learned from studies using healthy dogs [5] and cats [1] as aging models, including nutritional interventions that delay naturally-occurring, age-related kidney disease, may well contribute to our 
understanding of the beneficial therapeutic interventions for aging in humans and management of CKD.

In cats, similar to humans, aging is associated with decreased GFR. Although supplementation with high quality proteins is recommended for humans to prevent loss of muscle mass and function [6], renal protective foods designed for cats are modified from typical maintenance foods by mildly restricting total protein, phosphorus, and sodium concentrations, increasing concentrations of vitamins and soluble fiber, increasing caloric density, and maintaining a neutral acid-balance [7]. In dogs and cats, these modifications delay the onset of uremia and death from complications of CKD compared with maintenance foods, as reviewed in References [7-9]. We have shown in previous studies in dogs that dietary interventions offset the effects of aging on serum fatty acid (FA) and carnitine metabolite concentrations [10], and that supplementing with increasing amounts of functional food bioactives (e.g., fish oil, lipoic acid, fruit and vegetables, and alternative protein sources) can temporarily reverse the age-associated decline in renal function and serum total protein [5]. In a previous study, healthy geriatric cats (mean age, 14.0 years) that were fed reduced protein and phosphorus foods, with added fish oil, L-carnitine, and medium-chain triglycerides for six months did not have altered LBM, GFR, or serum albumin [1]. In the current study, we further modified the cat food and hypothesized that dietary supplementation of a control maintenance food using different protein sources, botanicals (fruit and vegetables), and increased amounts of functional lipids (fish oil) would delay the age-associated decline in GFR and LBM in a senior-adult cat model (mean age 12.2 years) compared with our previous study in geriatric cats [1]. The human equivalent of senior-adult cats aged 11 to 14 years is 60 to 72 years [11]. We found beneficial effects for offsetting sarcopenia and chronic inflammation associated with aging, as well as improvement in renal function (GFR), after consuming foods supplemented with bioactive ingredients for six months in senior-adult cats, thus conferring health benefits.

\section{Materials and Methods}

All study protocols and this study were reviewed and approved by the Institutional Animal Care and Use Committee, Hill's Pet Nutrition, Inc. (Topeka, KS, USA; Permit Number: CP360), and complied with the National Institutes of Health Guide for the Care and Use of Laboratory Animals [12]. Cats were considered healthy with no evidence of chronic systemic disease based on results of an annual physical examination, complete blood count $(\mathrm{CBC})$, serum biochemistries, and urinalysis. Cats were housed in their normal communal groups, with indoor runs and access to covered porches. Cats also had access to natural light that varied with seasonal changes. All cats were provided with regular opportunities to exercise, and with access to toys. Cats were owned by the commercial funders of this research or their affiliates, who gave permission for them to be included in this study.

\subsection{Participants and Study Design}

After being fed the same maintenance food for 30 days, cats were blocked for gender and divided into their randomly assigned groups. For the feeding trial, the study design consisted of three groups of cats ( $n=14$ or 15 per group) fed either control food or control food supplemented with functional lipids (fish oil), antioxidants and botanical (fruit and vegetables), and different protein sources [functional food one (FF1) and functional food two (FF2)] for six months. Group sizes were based on a previous study in dogs, ranging in age from 3.1 to 14.8 years, whereby we showed that dietary interventions counterbalanced the effects of age on serum FA and carnitine metabolite concentrations [10]. All cats had access to electronic feeders, and fresh food was offered daily with amounts calculated to maintain body weight; water was available ad libitum. Daily food intake (g/day) was recorded for each cat.

Studies were conducted using 44 healthy, senior-adult cats ranging in age from 10.7 to 14.0 years ( 25 ovariohysterectomized females and 19 neutered males). All cats were of domestic shorthair breed (Table 1). Mean age was 12.2 years; mean initial body weight was $4.5 \mathrm{~kg}$. Inclusion criteria were cats between 10.7 and 14.0 years of age. Cats were excluded if they were known to have problems eating new foods or problems with repeated blood sampling, and/or any diagnosed disease condition. 
The criterion for removal from the study was development of any condition whereby removal would benefit the animal, including any cat refusing to eat, or inadequate food intake resulting in weight loss greater than $15 \%$ of body weight. All cats completed the study.

Table 1. Demographic data at baseline for senior-adult cats fed control food, or functional foods 1 and 2.

\begin{tabular}{lccccccccc}
\hline \multirow{2}{*}{ Demographics } & \multicolumn{3}{c}{ Control Food $(n=15)$} & \multicolumn{2}{c}{ Functional Food 1 $(n=15)$} & \multicolumn{2}{c}{ Functional Food 2 $(n=14)$} \\
\cline { 2 - 11 } & Mean & SD & Range & Mean & SD & Range & Mean & SD & Range \\
\hline Age, years & 12.0 & 0.9 & $10.9-13.7$ & 12.3 & 0.5 & $10.9-14.0$ & 12.2 & 1.0 & $10.7-14.0$ \\
\hline Sex & \multicolumn{2}{c}{9 females; 6 males } & \multicolumn{2}{c}{9 females; 6 males } & \multicolumn{2}{c}{7 females; 7 males } \\
\hline Body weight, $\mathrm{kg}$ & 4.45 & 0.84 & $3.31-5.82$ & 4.73 & 1.11 & $3.22-6.62$ & 4.23 & 0.78 & $3.11-5.82$ \\
\hline Body lean, $\mathrm{kg}$ & 3.29 & 0.46 & $2.67-3.96$ & 3.53 & 0.74 & $2.52-4.81$ & 3.38 & 0.56 & $2.66-4.58$ \\
\hline Body fat, $\mathrm{kg}$ & 1.05 & 0.58 & $0.30-2.15$ & 1.08 & 0.51 & $0.31-1.96$ & 0.74 & 0.37 & $0.27-1.45$ \\
\hline
\end{tabular}

Serum and plasma analyses were completed on blood collected at baseline and after consuming control or test foods for 1.5, 3, and 6 months (four blood collections total). Analyses included plasma metabolomics, serum FA composition, biomarkers of renal function [Cr, SDMA, blood urea nitrogen (BUN)], and other serum biochemistries. Total, fat, and lean body mass were measured by dual-energy X-ray absorptiometry (DXA-QDR-4500, Hologic) using manufacturer-supplied software. Blood was also collected at these same time points to assess GFR by iohexol clearance. Food intake was recorded daily, and body weight was recorded weekly during the 30-day pre-trial period and every six weeks during the feeding trial.

To determine the effect of age on body weight, lean body percent, serum biomarkers, and GFR, we also studied a cohort of younger cats (20 healthy, young-adult cats from the same colony). Criteria for inclusion were age $>1$ but $<6$ years. These cats all had normal serum SDMA, Cr, BUN, albumin, and total protein concentrations. Their LBM was also evaluated. These cats lacked historical or physical evidence of confounding disease at the time of inclusion. Mean age of these young adult cats was 3.5 years (range: 2.1 to 4.9 years). There were three ovariohysterectomized females and 17 neutered males. Mean BW was $4.53 \mathrm{~kg}$ (range: 3.44 to $5.98 \mathrm{~kg}$ ). Mean LBM and mean body fat were 3.70 and $0.71 \mathrm{~kg}$, respectively. These cats were consuming age-appropriate adult maintenance foods at the time of testing.

\subsection{Foods}

Prior to beginning the study, senior-adult cats consumed the same maintenance food for 30 days (Table 2). This pre-trial food was a complete and balanced feline maintenance food that was designed to meet the nutritional requirements of senior-adult cats, but contained no added functional ingredients such as carnitine, fish oil, fruit and vegetables, pea protein, or wet meat chicken. It did contain added $\alpha$-tocopheryl acetate at $49 \mathrm{IU} / \mathrm{kg}$ and ascorbyl monophosphate at $97 \mathrm{mg} / \mathrm{kg}$. After 30 days, cats were assigned to one of three treatment groups ( $n=14$ or 15 each; control, FF1, and FF2). The control food was similar to the pre-trial food in protein and fat content, but had added fiber and fish oil. All cat foods were prepared by Hill's Pet Nutrition, Inc., and met the nutritional requirements for adult cats ( $\geq 1$ year) as established by the Association of American Feed Control Officials (AAFCO). Food was available in dry form only. Macronutrient composition and FA content of foods was determined by a commercial laboratory (Eurofins Scientific, Inc., Des Moines, IA, USA). Proximate analyses were completed using the following Association of Analytical Communities (AOAC) methods: moisture-AOAC 930.15; protein-AOAC 2001.11; fat-AOAC 954.02; fiber-AOAC 962.09; and ash-AOAC 942.05. Carbohydrate composition was determined by calculation. Food composition, expressed as percentage of food, as fed, is shown in Table 2. Vitamin, mineral, and FA analyses 
were performed by the same commercial laboratory. Fatty acid composition was determined by gas chromatography of FA methyl esters, and were expressed as $\mathrm{g} / 100 \mathrm{~g}$ of FAs as fed.

Table 2. Food composition ${ }^{1}$ of pre-trial ${ }^{2}$, control $^{3}$, and functional foods ${ }^{4}$.

\begin{tabular}{|c|c|c|c|c|}
\hline Food/Nutrient & Pre-Trial Food & Control Food & Functional Food 1 & Functional Food 2 \\
\hline Added fish oil, $\%$ & 0 & 0.1 & 0.5 & 0.5 \\
\hline Fruit and vegetables, \% & 0 & 0 & 1.9 & 4.0 \\
\hline Pea protein, $\%$ & 0 & 0 & 19.7 & 43.6 \\
\hline Wet meat chicken, $\%$ & 0 & 0 & 16.0 & 15.5 \\
\hline Chicken meal, \% & 28.0 & 19.4 & 0 & 0 \\
\hline Corn gluten meal, $\%$ & 15.7 & 19.2 & 16.0 & 0 \\
\hline Moisture & 6.50 & 6.77 & 6.78 & 6.34 \\
\hline Protein & 33.43 & 32.58 & 30.24 & 31.77 \\
\hline Fat & 21.12 & 20.84 & 16.17 & 15.25 \\
\hline Atwater Energy, ${ }^{5} \mathrm{kcal} / \mathrm{kg}$ & 4092 & 4019 & 3810 & 3746 \\
\hline Ash & 4.94 & 5.16 & 5.57 & 6.21 \\
\hline Crude fiber & 1.8 & 3.0 & 1.9 & 2.2 \\
\hline Calcium & 0.78 & 0.85 & 0.80 & 0.78 \\
\hline Phosphorus & 0.84 & 0.74 & 0.76 & 0.83 \\
\hline Sodium & 0.46 & 0.30 & 0.36 & 0.36 \\
\hline Total tocopherols, IU/kg & 49 & 1059 & 1137 & 1268 \\
\hline Vitamin $\mathrm{C}, \mathrm{mg} / \mathrm{kg}$ & 97 & 192 & 231 & 231 \\
\hline Palmitic acid [16:0] & 4.27 & 4.11 & 2.97 & 3.06 \\
\hline Stearic acid [18:0] & 2.01 & 1.90 & 0.69 & 0.72 \\
\hline linoleic acid (LA) [18:2 $(n-6)]$ & 3.70 & 3.72 & 3.55 & 3.49 \\
\hline alpha linolenic acid ( $\alpha$ LA) $[18: 3(n-3)]$ & 0.18 & 0.20 & 0.28 & 0.33 \\
\hline arachidonic acid (ARA) [20:4 $(n-6)]$ & 0.12 & 0.12 & 0.04 & 0.04 \\
\hline eicosapentaenoic acid (EPA) [20:5 $(n-3)]$ & 0.01 & 0.03 & 0.09 & 0.10 \\
\hline docosapentaenoic acid (DPA) [22:5 $(n-3)]$ & 0.01 & 0.02 & 0.02 & 0.02 \\
\hline docosahexaenoic acid (DHA) [22:6 $(n-3)]$ & 0.01 & 0.02 & 0.06 & 0.06 \\
\hline saturated fatty acids (SFA) 6 & 6.69 & 6.42 & 3.90 & 4.02 \\
\hline monounsaturated fatty acids (MUFA) ${ }^{7}$ & 8.01 & 7.71 & 5.69 & 5.60 \\
\hline polyunsaturated fatty acids (PUFA) ${ }^{8}$ & 4.22 & 4.07 & 4.12 & 4.03 \\
\hline$(n-6)$ fatty acids $\left(\mathrm{FA}^{9}\right)$ & 4.03 & 3.80 & 3.67 & 3.61 \\
\hline$(n-3)$ fatty acids (FA) ${ }^{10}$ & 0.19 & 0.27 & 0.45 & 0.42 \\
\hline$(n-6):(n-3)$ ratio & 21.2 & 14.1 & 8.2 & 8.6 \\
\hline
\end{tabular}

${ }^{1}$ All analytical values are expressed as percentage of food, as fed, unless otherwise indicated. ${ }^{2}$ Pre-trial food was prepared by Hill's Pet Nutrition, Inc. Ingredient label in order of preponderance is as follows: poultry by-product meal, corn, corn starch, corn gluten meal, pork fat, cellulose, palatability enhancer, taurine, vitamins, and minerals. Food contained no added functional ingredients such as carnitine, fish oil, fruit and vegetables, pea protein, or wet meat chicken. ${ }^{3}$ Control food was prepared by Hill's Pet Nutrition, Inc. and was similar to the pre-trial food in protein and fat content, but had added fiber, fish oil, $\alpha$-tocopheryl acetate, and ascorbyl monophosphate. Ingredient label in order of preponderance is as follows: poultry by-product meal, corn gluten meal, rice, pork fat, corn, soybean mill run, lysine, lactic acid, taurine, carnitine, fish oil, vitamins, and minerals. ${ }^{4}$ The two functional foods differed from control food in degree of supplementation with functional lipids, presence of botanicals (fruit and vegetables), and pea and chicken protein concentrations. Ingredient label in order of preponderance for functional food 1 is as follows: rice, pea protein concentrate, chicken, corn gluten meal, oats, lactic acid, beet pulp, tomato pomace, methionine, broccoli, fish oil, taurine, carnitine, cysteine, vitamins, and minerals. Ingredient label in order of preponderance for functional food 2 is as follows: pea protein concentrate, chicken, rice, oats, beet pulp, lactic acid, broccoli, tomato pomace, methionine, fish oil, taurine, carnitine, cysteine, vitamins, and minerals. ${ }^{5}$ Energy calculated using the modified Atwater factors as described [13]. ${ }^{6}$ Sum of the saturated fatty acids (SFA): 8:0 + 10:0 + $11: 0+12: 0+14: 0+15: 0+16: 0+17: 0+18: 0+20: 0+22: 0+24: 0 .{ }^{7}$ Sum of the monounsaturated fatty acids (MUFA): $14: 1+15: 1+16: 1+17: 1+18: 1+20: 1+22: 1+24: 1 .{ }^{8}$ Sum of the polyunsaturated fatty acids (PUFA): $18: 2(n-6)+$ $18: 3(n-6)+18: 3(n-3)+18: 4(n-3)+20: 2(n-6)+20: 3(n-6)+20: 3(n-3)+20: 4(n-6)+20: 4(n-3)+20: 5(n-3)$ $+21: 5(n-3)+22: 2(n-6)+22: 4(n-6)+22: 5(n-6)+22: 5(n-3)+22: 6(n-3) .{ }^{9}$ Sum of the $(n-6)$ fatty acid (FA) listed above. ${ }^{10}$ Sum of the $(n-3)$ FA listed above.

Foods were similar in that they all contained L-carnitine $(550 \mathrm{mg} / \mathrm{kg})$, vitamin $\mathrm{C}$ as ascorbyl monophosphate $(190 \mathrm{mg} / \mathrm{kg}$ ), and vitamin $\mathrm{E}$ as $\alpha$-tocopherol (1050 IU/kg). Functional foods both contained increased long-chain FA as fish oil (0.5\%). FF1 and FF2 were similar in that they both contained increased amounts of fruit and vegetables, pea protein, and wet meat chicken compared with control food. FF2 had increased amounts of fruit and vegetables compared with FF1, i.e., beet pulp increased from $0.7 \%$ to $2.0 \%$, tomato pomace increased from $0.7 \%$ to $1.0 \%$, and broccoli powder increased from $0.5 \%$ to $1.0 \%$, with an overall increase of fruit and vegetables from $1.9 \%$ to $4.0 \%$. FF2 also 
had increased pea protein from $19.7 \%$ to $43.6 \%$ compared with FF1. FF1 had increased corn gluten meal from $0 \%$ to $16.0 \%$ compared with FF2 (Table 2).

Control and test foods had comparable concentrations (within analytical variance of overall mean) of protein, and had similar modified Atwater energy caloric content. The control food contained lower concentrations of long-chain polyunsaturated fatty acids (PUFA), supplied as eicosapentaenoic acid (EPA) and docosahexaenoic acid (DHA). Compared with control food, FF1 and FF2 contained less arachidonic acid (ARA), more EPA and DHA, and higher concentrations of saturated fatty acids (SFA) and monounsaturated fatty acids (MUFA) (Table 2).

\subsection{Chemical Analyses for Biomarkers and Metabolites}

Blood was collected from each cat following an overnight fast at each time period. Serum concentrations of albumin, total protein, and other biochemicals were measured by the in-house laboratory (Roche Diagnostics, Cobas 6000 series, c501 module, Indianapolis, IN). The normal reference intervals for serum $\mathrm{Cr}$ ( 0.8 to $1.7 \mathrm{mg} / \mathrm{dL}$ ) and BUN (14.8 to $29.4 \mathrm{mg} / \mathrm{dL}$ ) had been determined historically. Liquid chromatography-mass spectroscopy was used to determine serum SDMA concentrations as previously described [2]. The upper limit of the reference interval for SDMA was determined by a commercial laboratory (IDEXX Laboratories, Inc., Westbrook, ME, USA) in healthy cats to be $<14$ $\mu \mathrm{g} / \mathrm{dL}$. Serum prostaglandin $\mathrm{E}_{2}\left(\mathrm{PGE}_{2}\right)$ concentrations were determined using a commercial $\mathrm{PGE}_{2}$ ELISA kit-monoclonal (performed by Cayman Chemical, Ann Arbor, MI using kit catalog number 514010). Results are reported as picograms $\mathrm{PGE}_{2}$ per deciliter serum. The intra-assay coefficient of variation $(\mathrm{CV})$ for $\mathrm{PGE}_{2}$ in the range of the standard curve for our samples was $\leq 6.6 \%$.

Fatty acid composition of serum samples was also determined by gas chromatography of FA methyl esters, with minor modifications [14] of the Folch et al. [15] method. Serum FA concentrations were expressed as $\mathrm{mg} / \mathrm{dL}$. Blood samples were also processed to collect plasma for metabolomic profiles, which were determined by a commercial laboratory (Metabolon, Durham, NC) as previously described [10]. For each metabolite, the median was set equal to one and all samples scaled accordingly.

The GFR in senior-adult cats was determined by iohexol clearance. Serum concentrations of iohexol were measured by a commercial laboratory (IDEXX Laboratories, Inc., Westbrook, ME, USA) using high performance liquid chromatography (HPLC) with ultraviolet detection. In brief, a single intravenous injection of iohexol (300 mg I/ $\mathrm{kg}$ body weight) was administered to cats and three serum samples were collected at 2, 3, and $4 \mathrm{~h}$ after iohexol injection. The HPLC method was modified from that described by De Baere et al. [16]. Standard curve linearity was 0.99 , accuracy was between 98-103\%, and intra- and inter-day precision was $<6 \%$ for all standard concentrations and no carryover was found between repeated injections of the highest stock standard and phosphate-buffered saline blank. The GFR was estimated from calculations made using a one-compartment model for serum iohexol clearance. The mean (range) GFR for senior-adult adult cats in this study was $1.92 \mathrm{~mL} / \mathrm{min} / \mathrm{kg}$ ( 1.78 to $2.29 \mathrm{~mL} / \mathrm{min} / \mathrm{kg}$ ). The GFR was calculated to be $2.08 \mathrm{~mL} / \mathrm{min} / \mathrm{kg}$ in the young-adult cats using a prediction equation: $\mathrm{GFR}=3.467-\mathrm{SDMA} \times 0.03323-\mathrm{Cr} \times 0.442757-$ age $\times 0.035227-\mathrm{mass}(\mathrm{kg}) \times$ 0.06765 , which was based on data from Hall et al. [2] that used a regression analysis and the statistically significant variables of age, body weight, and SDMA and Cr concentrations.

\subsection{Statistical Methods}

Statistical analyses were performed in SAS version 9.4 (SAS Institute, Cary, NC, USA). Response variables were tested for normal distribution using the Kolmogorov-Smirnov test, skewness and kurtosis measures, and inspection of plots of the data in PROC UNIVARIATE. Based on these tests, all data (except metabolomics data) were normally distributed.

The effect of age on LBM, body weight, GFR, and serum biomarker concentrations was analyzed using data from senior-adult cats ( $n=44$; range: 10.7 to 14.0 years) at baseline and at six months, overall and by test food groups, compared with data from young-adult cats $(n=20$; range: 2.1 to 4.9 years) using unpaired $t$-tests (PROC TTEST). 
To analyze the effect of feeding RPF on circulating biomarkers, body composition, renal function, and $\mathrm{PGE}_{2}$ concentrations, data from senior-adult cats were analyzed as repeated-measures-in-time, randomized design using GLM in PROC MIXED and the Satterthwaite approximation to determine the denominator degrees of freedom for the tests of fixed effects. Animal was the experimental unit. Data are reported as least square means (LSM) \pm standard error of the mean (SEM). Fixed effects in the model were food group (control, FF1, FF2), time (0 and 6 months), and their interaction. We report $p$ values for food effect and time effect.

To determine the effect of intervening with separate foods, we used a paired $t$-test to compare values at six months with those at baseline. Then to determine whether food effects were different between control food and functional food diets, we compared the change in values at six months and baseline (T6 - T0; which accounts for differences in baseline values) for cats fed control and experimental foods (change for cats fed FF1 vs. change for control; and change for cats fed FF2 vs. change for control). This was accomplished using an unpaired $t$-test.

Metabolomic data were analyzed only for change from three months to baseline (T3 - T0). The end of study metabolomics data were not assessed because samples were not run at the same time as samples collected at baseline and three months. Obtained metabolite values were $\log _{2}$ transformed, and statistics were performed on transformed values. $\log _{2}$-transformed metabolite values at baseline were subtracted from transformed values at three months. Thus, each cat served as its own control, which allowed for the reporting of the change in a given metabolite that was induced by food rather than a cross-sectional assessment at one time. Difference values are presented as $\log _{2}$ fold change from baseline to three months $\left(\log _{2} \mathrm{FC}\right)$.

The deltas of values at three months minus baseline for each group for the global serum metabolome were assessed with the Metaboanalyst platform v4.0 [17]. Sparse partial least squares analysis (SPLS) was used to distinguish between food groups (number of components $=2$, validation method $=5$ fold cross validation, number of predictors $=20$ ) and Random Forest was used to detect metabolite predictors of group identity (number of trees $=2000$, number of predictors $=20$, Randomness $=$ On).

Statistical analyses for discrete metabolite classes (glutathione, methylation, and postbiotics) and their constituent metabolites were performed in JMP version 13.1-14.2 (SAS Institute, Cary, NC, USA). Determination of whether the change from baseline of a class of lipids or postbiotics differed across the study groups was performed by multivariate analysis of variance (MANOVA) using the Identity Function, which fit a model for each metabolite individually and then jointly tested the models together. The separate MANOVA $p$ values for Wilks' lambda, Pillai's trace, Hotelling-Lawley, and Roy's max root are reported in Table S1. Only where $p$ values for each of these MANOVA metrics were $\leq 0.05$ was the multivariate metabolite class considered significantly impacted by food and allowed to proceed for further analysis. One-way analysis of variance (ANOVA) was used to examine the number of changes from baseline for metabolites resulting from control food and intervention with functional foods. For ANOVA, to account for the high dimensionality of metabolomics data, false discovery rate (FDR)-correcting q-values were generated for all metabolites using the " $q$-value" function in the R package $q$-value v2.14.1 (Storey, Bass, Dabney, \& Robinson, 2014). Statistical significance was assigned to a metabolite where both of the following criteria were met: $p \leq 0.05$ and FDR $q \leq 0.1$.

The sequential statistical process for testing whether changes from baseline of metabolite classes and class constituents were significant, and further whether these changes in individual metabolites differed by group was as follows: When MANOVA determined significance for a multivariate biochemical class, the delta for each metabolite in that class was subsequently assessed for a group effect by univariate ANOVA to determine which metabolites in that class drove the significance observed for the class as a whole. Then, the degree to which a given metabolite exhibited a change from baseline that was significantly different from zero within a group was assessed by paired $t$-test. Finally, the relative change from baseline for each metabolite was compared for all pairs of food groups by post hoc analysis using Tukey's honestly significant differences (HSD). 


\section{Results}

\subsection{Effect of Age on Lean Body Percent, GFR, and Serum Biochemistries}

At baseline, senior-adults cats (10.7 to 14.0 years) had lower lean body percent ( $p=0.02$; Table 3 ) and serum albumin $(p<0.01)$, and higher fat body fat body mass $(p=0.03)$ and fat body percent $(p<0.01)$ compared with young-adult cats (2.1 to 4.9 years). Serum total protein and body weight were not different. At baseline senior-adult cats had lower serum urea concentration $(p=0.02)$ and a trend toward lower GFR ( $p=0.09$ ) compared with young-adult cats. Serum concentrations of Cr and SDMA were not different between senior-adult and young adult cats. 
Table 3. Effect of feeding control ${ }^{1}$ or two functional foods (FF1 and FF2) ${ }^{2}$ for six months (T6) on body composition, renal function, and serum metabolite concentrations in senior-adult cats ${ }^{3}$ (least square mean, LSM \pm standard error of the mean, SEM) compared with their baseline values (T0), and values for young-adult cats ${ }^{4}$ (LSM).

\begin{tabular}{|c|c|c|c|c|c|c|c|c|c|c|}
\hline \multirow{2}{*}{ Variables } & \multirow{2}{*}{ Young-Adult Cats } & \multicolumn{4}{|c|}{$\begin{array}{c}\text { Senior-Adult Cats at Baseline (T0) and after Feeding for } \\
\text { Six months (T6) }\end{array}$} & \multirow{2}{*}{ SEM } & \multicolumn{4}{|c|}{$p$-Values ${ }^{5}$ Senior-Adult Cats vs. Young-Adult Cats } \\
\hline & & $\begin{array}{l}\text { Senior-Adult } \\
\text { Cats (T0) }\end{array}$ & Control (T6) & FF1 (T6) & FF2 (T6) & & $\begin{array}{l}\text { Senior-Adult } \\
\text { Cats (T0) }\end{array}$ & Control (T6) & FF1 (T6) & FF2 (T6) \\
\hline \multicolumn{11}{|l|}{$\begin{array}{l}\text { Body Mass and } \\
\text { Composition: }\end{array}$} \\
\hline Body Weight, $\mathrm{kg}^{6}$ & 4.53 & 4.47 & 4.44 & 4.63 & 4.20 & 0.18 & 0.66 & 0.76 & 0.70 & 0.25 \\
\hline Lean Body Mass, $\mathrm{kg}^{6}$ & 3.70 & 3.40 & 3.33 & 3.57 & $3.60 *$ & 0.02 & 0.06 & 0.09 & 0.53 & 0.52 \\
\hline Fat Body Mass, $\mathrm{kg}^{6}$ & 0.70 & 0.96 & 0.99 & 0.95 & $0.53 *$ & 0.11 & 0.03 & 0.04 & 0.08 & 0.21 \\
\hline Lean Body, \% & 81.6 & 76.9 & 75.9 & 78.2 & 84.9 & 1.9 & 0.02 & 0.02 & 0.14 & 0.16 \\
\hline Fat Body, $\%$ & 14.4 & 20.6 & 21.6 & $19.2 *$ & $12.4^{*}$ & 1.79 & $<0.01$ & $<0.01$ & 0.04 & 0.39 \\
\hline \multicolumn{11}{|l|}{ Renal Function: } \\
\hline $\begin{array}{l}\text { Glomerular Filtration } \\
\text { Rate, } \mathrm{mL} / \mathrm{min} / \mathrm{kg}^{7}\end{array}$ & $2.08^{7}$ & 1.92 & $2.09 *$ & $2.32 *$ & $2.13 *$ & 0.13 & 0.09 & 0.91 & 0.21 & 0.87 \\
\hline \multicolumn{11}{|l|}{ Serum Metabolites: } \\
\hline Creatinine, $\mathrm{mg} / \mathrm{dL}$ & 1.31 & 1.22 & 1.25 & 0.99 * & 1.17 & 0.049 & 0.11 & $<0.01$ & $<0.01$ & $<0.01$ \\
\hline $\begin{array}{l}\text { Symmetric } \\
\text { dimethylarginine } \\
\text { (SDMA), } \mu \mathrm{g} / \mathrm{dL}\end{array}$ & 11.5 & 11.1 & $10.3 *$ & $9.1 *$ & 10.8 & 0.4 & 0.79 & 0.01 & $<0.01$ & 0.15 \\
\hline $\begin{array}{l}\text { Blood urea nitrogen } \\
\text { (BUN), mg/dL }\end{array}$ & 21.82 & 20.33 & $21.30 *$ & $22.35 *$ & 23.21 * & 0.45 & 0.02 & 0.56 & 0.55 & 0.12 \\
\hline Total Protein, mg/dL & 6.71 & 6.68 & 6.97 & $7.37^{*}$ & $7.42 *$ & 0.14 & 0.67 & 0.17 & $<0.01$ & $<0.01$ \\
\hline Albumin, mg/dL & 3.31 & 2.82 & $2.67 *$ & 2.78 & 2.68 & 0.07 & $<0.01$ & $<0.01$ & $<0.01$ & $<0.01$ \\
\hline Prostaglandin, pg/dL & $\mathrm{NA}^{8}$ & 162 & $116^{*}$ & $94^{*}$ & 149 & 8.5 & NA & NA & NA & NA \\
\hline
\end{tabular}

${ }^{1}$ Control food was prepared by Hill's Pet Nutrition, Inc. and was similar to the pre-trial food in protein and fat content, but had added fiber, fish oil, $\alpha$-tocopheryl acetate and ascorbyl monophosphate. 2 The two functional foods differed from control food in degree of supplementation with functional lipids, botanicals (fruit and vegetables), as well as pea and chicken protein protein compare significantly $(p<0.05)$ different compared with their baseline values. ${ }^{6}$ Body mass and composition were determined by dual-energy X-ray absorptiometry scan analysis. ${ }^{7}$ Glomerular filtration rate (GFR) was calculated in the young-adult cats using a prediction equation which was based on data from Hall et al. [2] that used a regression analysis and the statistically significant variables of age, body weight, and symmetric dimethylarginine (SDMA) and serum creatinine $(\mathrm{Cr})$ concentrations: GFR $=3.467-\mathrm{SDMA} \times 0.03323-\mathrm{Cr} \times 0.442757-$ age $\times$ 0.035227 - mass $(\mathrm{kg}) \times 0.06765 .{ }^{8}$ Not analyzed. 
3.2. Effect of Feeding Renal Protective Foods on Body Weight, Lean Body Percent, GFR, Serum Biomarkers, and $P G E_{2}$ across Time

Feeding RPF for six months did not affect ( $p=0.98$; Table 4 ) total body weight change (average: $-0.07 \mathrm{~kg}$ ), but increased ( $p<0.01$ ) lean body percent in senior-adult cats (average change: $2.7 \%$ ). Cats fed FF1 and FF2 gained more lean body percent (both $p<0.01$ ) compared with cats fed control food. Cats fed FF2 had higher LBM and lower fat body mass compared with their baseline values (both $p<0.05$ ). Consumption of both FF1 and FF2 led to decreased fat body percent at six months $(p<0.05$ for both groups).

Table 4. Effect of feeding control ${ }^{1}$ or two functional foods (FF1 and FF2) ${ }^{2}$ for six months (T6) on body composition, renal function, and serum metabolite concentrations in cats compared with their baseline values (T0) ${ }^{3}$.

\begin{tabular}{|c|c|c|c|c|c|c|c|c|}
\hline \multirow{2}{*}{ Variables } & \multicolumn{3}{|c|}{ Renal-Protective Foods } & \multirow{2}{*}{ SEM } & \multirow{2}{*}{$\begin{array}{c}p \text {-Values } \\
\text { for Food } \\
\text { Effect }\end{array}$} & \multicolumn{2}{|c|}{$\begin{array}{l}p \text {-Values for Food } \\
\text { Comparisons }^{5}\end{array}$} & \multirow{2}{*}{$\begin{array}{c}p \text {-Values } \\
\text { for Time } \\
\text { Effect }^{4}\end{array}$} \\
\hline & Control & FF1 & FF2 & & & $\begin{array}{l}\text { FF1 vs. } \\
\text { Control }\end{array}$ & $\begin{array}{l}\text { FF2 vs. } \\
\text { Control }\end{array}$ & \\
\hline \multicolumn{9}{|c|}{ Body Mass and Composition: } \\
\hline \multicolumn{9}{|l|}{ Body Weight, $\mathrm{kg}^{6}$} \\
\hline Initial, $\mathrm{T0}$ & 4.45 & 4.73 & 4.23 & 0.25 & & & & \\
\hline Change, $\mathrm{T} 6-\mathrm{T} 0$ & -0.07 & -0.10 & -0.03 & 0.07 & 0.58 & 0.37 & 0.83 & 0.98 \\
\hline \multicolumn{9}{|l|}{ Lean Body, $\%{ }^{7}$} \\
\hline Initial, $\mathrm{T0}$ & 75 & 75.4 & 80.4 & 2.1 & & & & \\
\hline Change, $\mathrm{T} 6-\mathrm{T} 0$ & 0.9 & 2.7 & 4.5 & 1.0 & $<0.01$ & $<0.01$ & $<0.01$ & $<0.01$ \\
\hline \multicolumn{9}{|l|}{ Renal Function: } \\
\hline \multicolumn{9}{|c|}{ Glomerular Filtration Rate, $\mathrm{mL} / \mathrm{min} / \mathrm{kg}$} \\
\hline Initial, T0 & 1.85 & 2.01 & 1.85 & 0.04 & & & & \\
\hline Change, T6 - T0 & 0.23 & 0.30 & 0.27 & 0.11 & 0.86 & 0.65 & 0.82 & $<0.01$ \\
\hline \multicolumn{9}{|c|}{ Serum Biochemistries: } \\
\hline \multicolumn{9}{|l|}{ Creatinine, $\mathrm{mg} / \mathrm{dL}$} \\
\hline Initial, T0 & 1.15 & 1.13 & 1.20 & 0.062 & & & & \\
\hline Change, $\mathrm{T} 6-\mathrm{T} 0$ & 0.04 & -0.19 & -0.05 & 0.047 & 0.07 & $<0.01$ & 0.2 & $<0.01$ \\
\hline \multicolumn{9}{|l|}{ SDMA, $\mu \mathrm{g} / \mathrm{dL}$} \\
\hline Initial, T0 & 10.9 & 10.9 & 11.1 & 0.29 & & & & \\
\hline Change, T6 - T0 & -0.67 & -1.76 & -0.31 & 0.33 & $<0.01$ & $<0.01$ & 0.85 & $<0.01$ \\
\hline \multicolumn{9}{|l|}{ BUN, mg/dL } \\
\hline Initial, T0 & 19.8 & 20.1 & 20.3 & 0.6 & & & & \\
\hline Change, T6 - T0 & 1.52 & 1.32 & 3.32 & 0.6 & 0.09 & 0.85 & 0.08 & $<0.01$ \\
\hline \multicolumn{9}{|c|}{ Total Protein, mg/dL } \\
\hline Initial, T0 & 7.22 & 6.44 & 6.39 & 0.05 & & & & \\
\hline Change, T6 - T0 & -0.10 & 0.82 & 1.02 & 0.11 & $<0.01$ & $<0.01$ & $<0.01$ & $<0.01$ \\
\hline \multicolumn{9}{|l|}{ Albumin, mg/dL } \\
\hline Initial, T0 & 2.83 & 2.8 & 2.77 & 0.05 & & & & \\
\hline Change, T6 - T0 & -0.33 & 0.04 & 0.01 & 0.05 & $<0.01$ & $<0.01$ & $<0.01$ & 0.04 \\
\hline
\end{tabular}

${ }^{1}$ Control food was prepared by Hill's Pet Nutrition, Inc. and was similar to the pre-trial food in protein and fat content, but had added fiber, fish oil, $\alpha$-tocopheryl acetate, and ascorbyl monophosphate. ${ }^{2}$ The two functional foods differed from control food in degree of supplementation with functional lipids, botanicals (fruit and vegetables), as well as pea and chicken protein concentrations. ${ }^{3}$ Values are LSM, $n=15$ (control), $n=15$ (FF1), $n=14$ (FF2). ${ }^{4}$ To determine food and time main effects, data were analyzed as repeated-measures-in-time, randomized design using GLM in PROC MIXED and the Satterthwaite approximation to determine the denominator degrees of freedom for the tests of fixed effects. ${ }^{5}$ To determine whether food effects were different between control food and functional food diets, we compared changes (difference between values at six months and baseline; T6 - T0) for cats fed control food and experimental foods (change for cats fed FF1 vs. change for control; and change for cats fed FF2 vs. change for control), using an unpaired $t$-test. ${ }^{6}$ Body mass and composition were determined by dual-energy X-ray absorptiometry scan analysis.

Feeding RPF increased serum total protein concentrations in senior-adult cats (average: $0.58 \mathrm{mg} / \mathrm{dL}$ ). Greater increases were observed for cats fed FF1 and FF2 (both $p<0.01$ ) compared with control food. The FF1- and FF2-associated increases were sufficient, such that when senior-adult cats in these two 
groups were compared with young adult cats, serum total protein concentrations were significantly higher (both $p<0.01$ ) after feeding RPF for six months. Feeding FF1 and FF2 maintained serum albumin concentrations over six months, whereas cats fed control food had a significant decrease in serum albumin after six months $(p<0.05)$.

Feeding RPF for six months increased $(p<0.01)$ GFR in senior-adult cats (average: $0.27 \mathrm{~mL} / \mathrm{min} / \mathrm{kg}$ ); increases in GFR group means ranged from $12.4 \%$ (control) to $14.9 \%$ (FF1) to $14.6 \%$ (FF2). The increases associated with feeding RPF were large enough, such that when senior-adult cats were compared with young adult cats, GFR were no longer significantly different from young adult cats (all $p>0.05$ ).

Feeding RPF for six months decreased $(p<0.01)$ SDMA concentrations (average: $-0.91 \mu \mathrm{g} / \mathrm{dL}$ ) such that SDMA was significantly (both $p \leq 0.01$ ) lower in cats fed control and FF1 compared with young adult cats. The SDMA change in cats fed FF1 was greater $(p<0.01)$ compared with cats fed control food. Feeding RPF also affected serum $\mathrm{Cr}(p<0.01)$ and BUN concentrations $(p<0.01)$. On average serum $\mathrm{Cr}$ concentrations decreased $(-0.07 \mathrm{mg} / \mathrm{dL})$ and BUN concentrations increased $(2.05 \mathrm{mg} / \mathrm{dL})$. After feeding for six months, when senior-adult cats were compared with young adult cats, serum $\mathrm{Cr}$ concentrations were significantly lower in all three groups of senior-adult cats $(p<0.01)$ whereas BUN concentrations were not different from young adult cats (all $p>0.05)$.

Feeding RPF for six months decreased serum PGE 2 concentrations (average: $-47 \pm 6.8 \mathrm{pg} / \mathrm{dL}$; Table 3). The change in concentration in cats fed control food and FF1 were significantly different $(p<0.001)$ compared with baseline.

\subsection{Effect of Feeding Renal Protective Foods on Major Serum Fatty Acid Concentrations across Time}

Feeding RPF for six months increased $(p<0.01)$ serum concentrations of the SFA, MUFA, PUFA, and $(n-3)$ PUFA classes in all cat groups (Table 5). Cats fed FF1 and FF2 had increases primarily in EPA and DHA, but also in palmitoleic (C16:1), oleic (C18:1), linoleic (C18:2), and alpha linolenic (C18:3) acids, and decreases in ARA concentrations. Cats fed control food had increases primarily in oleic (C18:1), linoleic (LA, C18:2), and alpha linolenic ( $\alpha$ LA, C18:3) FA concentrations. The decrease in $(n-6):(n-3)$ PUFA ratio $(p<0.01)$ was similar in cats fed all three foods. Cats fed control food had a greater change in concentrations of $(n-6)$ PUFA (positive) vs. cats fed FF1 and FF2 (negative; both $p<0.01)$ and a smaller change in concentrations of $(n-3)$ PUFA (positive) vs. cats fed FF1 and FF2 (positive; both $p<0.01$ ). Cats fed control food had greater changes in MUFA $(p=0.04)$ and PUFA $(p=0.04)$ concentrations compared with cats fed FF1. No significant treatment group differences (food effects of FF1 or FF2 vs. control) were observed for SFA concentrations. 
Table 5. Effect of feeding control ${ }^{1}$ or one of two functional foods (FF1 and FF2) ${ }^{2}$ for six months (T6) on serum concentrations of major fatty acids (FAs) in cats compared with their baseline values (T0) ${ }^{3}$.

\begin{tabular}{|c|c|c|c|c|c|c|c|c|}
\hline \multirow{2}{*}{ Fatty Acids (mg/dL) } & \multicolumn{3}{|c|}{ Renal Protective Foods } & \multirow{2}{*}{ SEM } & \multirow{2}{*}{$\begin{array}{c}p \text {-Values } \\
\text { for Food } \\
\text { Effect }^{4}\end{array}$} & \multicolumn{2}{|c|}{$\begin{array}{l}p \text {-Values for Food } \\
\text { Comparisons }{ }^{5}\end{array}$} & \multirow{2}{*}{$\begin{array}{l}p \text {-Values } \\
\text { for Time } \\
\text { Effect }^{4}\end{array}$} \\
\hline & Control & FF1 & FF2 & & & $\begin{array}{l}\text { FF1 vs. } \\
\text { Control }\end{array}$ & $\begin{array}{l}\text { FF2 vs. } \\
\text { Control }\end{array}$ & \\
\hline \multicolumn{9}{|l|}{ Individual: } \\
\hline C16:0, T0 & 24.5 & 24.3 & 22.5 & 1.2 & & & & \\
\hline Change, T6 - T0 & +1.1 & +0.61 & +0.53 & 1.0 & 0.19 & 0.52 & 0.25 & 0.51 \\
\hline C16:1, T0 & 0.76 & 0.63 & 0.66 & 0.04 & & & & \\
\hline Change, T6 - T0 & +0.57 & +0.31 & +0.50 & 0.06 & 0.07 & $<0.01$ & 0.34 & $<0.01$ \\
\hline C18:0, T0 & 43.9 & 39.7 & 37.1 & 1.1 & & & & \\
\hline Change, T6 - T0 & +0.5 & +2.2 & -0.4 & 0.7 & $<0.01$ & 0.10 & 0.36 & 0.07 \\
\hline C18:1, T0 & 22.5 & 24.6 & 21.4 & 1.1 & & & & \\
\hline Change, T6 - T0 & +3.5 & +1.5 & +2.3 & 0.7 & 0.33 & 0.01 & 0.14 & $<0.01$ \\
\hline $\mathrm{C} 18: 2(\mathrm{n}-6), \mathrm{T} 0$ & 48.4 & 51.6 & 42.7 & 1.2 & & & & \\
\hline Change, T6 - T0 & +4.6 & +0.7 & +2.3 & 1.1 & 0.26 & 0.01 & 0.13 & $<0.01$ \\
\hline C18:3 (n - 3), T0 & 0.00 & 0.00 & 0.00 & 0.00 & & & & \\
\hline Change, T6 - T0 & +0.07 & +0.08 & +0.06 & 0.01 & 0.88 & 0.45 & 0.19 & $<0.01$ \\
\hline C20:4 (n-6), T0 & 18.1 & 16.7 & 15.6 & 0.5 & & & & \\
\hline Change, T6 - T0 & -1.4 & -4.1 & -4.6 & 0.5 & $<0.01$ & $<0.01$ & $<0.01$ & $<0.01$ \\
\hline $\mathrm{C} 20: 5(\mathrm{n}-3), \mathrm{T} 0$ & 0.09 & 0.09 & 0.09 & 0.01 & & & & \\
\hline Change, T6 - T0 & +0.77 & +1.79 & +1.81 & 0.17 & $<0.01$ & $<0.01$ & $<0.01$ & $<0.01$ \\
\hline $\mathrm{C} 22: 5(\mathrm{n}-3), \mathrm{T} 0$ & 0.62 & 0.56 & 0.63 & 0.03 & & & & \\
\hline Change, T6 - T0 & +0.56 & +1.18 & +0.98 & 0.11 & $<0.01$ & $<0.01$ & 0.01 & $<0.01$ \\
\hline C22:6 $(\mathrm{n}-3), \mathrm{T} 0$ & 2.05 & 2.53 & 2.41 & 0.09 & & & & \\
\hline Change, $\mathrm{T} 6-\mathrm{T} 0$ & +1.18 & +2.99 & +2.30 & 0.28 & $<0.01$ & $<0.01$ & $<0.01$ & $<0.01$ \\
\hline \multicolumn{9}{|l|}{ Sums: } \\
\hline $\mathrm{SFA}^{6}, \mathrm{~T} 0$ & 68.5 & 64.1 & 59.7 & 1.7 & & & & \\
\hline Change, T6 - T0 & +1.8 & +3.1 & +0.3 & 1.1 & 0.19 & 0.44 & 0.36 & $<0.01$ \\
\hline MUFA $^{7}, \mathrm{~T} 0$ & 23.2 & 25.2 & 22.1 & 0.6 & & & & \\
\hline Change, T6 - T0 & +3.8 & +2.0 & +2.8 & 0.6 & 0.51 & 0.04 & 0.23 & $<0.01$ \\
\hline PUFA $^{8}$, T0 & 72.5 & 75.3 & 64.5 & 1.8 & & & & \\
\hline Change, $\mathrm{T} 6-\mathrm{T} 0$ & +6.2 & +2.1 & +2.5 & 1.4 & 0.02 & 0.04 & 0.07 & $<0.01$ \\
\hline$(\mathrm{n}-6)$ PUFA $^{9}$, T0 & 70.4 & 72.7 & 62.0 & 1.7 & & & & \\
\hline Change, T6 - T0 & +4.2 & -2.7 & -1.7 & 1.4 & $<0.01$ & $<0.01$ & $<0.01$ & 0.35 \\
\hline$(n-3)$ PUFA $^{10}$, T0 & 2.1 & 2.6 & 2.5 & 0.2 & & & & \\
\hline Change, T6 - T0 & +2.0 & +4.9 & +4.2 & 0.5 & $<0.01$ & $<0.01$ & $<0.01$ & $<0.01$ \\
\hline \multicolumn{9}{|l|}{ Ratios: } \\
\hline$(n-6):(n-3), T 0$ & 35.4 & 28.5 & 26.3 & 2.0 & & & & \\
\hline Change, T6 - T0 & -13.7 & -14.3 & -13.0 & 1.8 & 0.96 & 0.79 & 0.79 & $<0.01$ \\
\hline PUFA:SFA, T0 & 1.06 & 1.19 & 1.08 & 0.01 & & & & \\
\hline Change, T6 - T0 & +0.06 & -0.03 & +0.043 & 0.01 & $<0.01$ & $<0.01$ & 0.14 & 0.12 \\
\hline \multicolumn{9}{|c|}{$\begin{array}{l}{ }^{1} \text { Control food was prepared by Hill's Pet Nutrition, Inc. and was similar to the pre-trial food in protein and fat } \\
\text { content, but had added fiber, fish oil, } \alpha \text {-tocopheryl acetate, and ascorbyl monophosphate. See ingredient label } \\
\text { in Table } 2 .{ }^{2} \text { The two functional foods differed from control food in degree of supplementation with functional } \\
\text { lipids, presence of botanicals (fruit and vegetables), and pea and chicken protein concentrations. See ingredient } \\
\text { labels in Table } 2 .{ }^{3} \text { Values are LSM, } n=15 \text { (control), } n=15 \text { (FF1), } n=14 \text { (FF2). }{ }^{4} \text { To determine food and time main } \\
\text { effects, data were analyzed as repeated-measures-in-time, randomized design using GLM in PROC MIXED and } \\
\text { the Satterthwaite approximation to determine the denominator degrees of freedom for the tests of fixed effects. } \\
{ }^{5} \text { To determine whether food effects were different between control food and functional food diets, we compared } \\
\text { changes (difference between values at six months and baseline; T6 - T0) for cats fed control food and experimental } \\
\text { foods (change for cats fed FF1 vs. change for control; and change for cats fed FF2 vs. change for control), using an } \\
\text { unpaired } t \text {-test. }{ }^{6-10} \text { See Table } 2 \text {. }\end{array}$} \\
\hline
\end{tabular}

\subsection{Effect of Functional Foods on Plasma Metabolite Concentrations of Antioxidants and Methylation Substrates after a Three-Month Feeding Period}

Metabolomic analysis performed on serum samples taken at T0 and T3 from cats identified 291 metabolites. Of these, one-way ANOVA showed that 101 (35\%) metabolites were significantly different $(p \leq 0.05)$ across the three dietary groups. Individual paired $t$-tests by cat groups indicated 
that 96 metabolites changed in the control group from baseline values ( $60 \mathrm{up}, 36 \mathrm{down}$; $\log _{2} \mathrm{FC}$ range $=-1.0$ to +1.6 ; mean (standard error, SE) $=0.07(0.02)$ ), 87 metabolites changed in the FF1 group (44 up, 43 down; $\log _{2} \mathrm{FC}$ range $=-1.6$ to +2.0 ; mean $(\mathrm{SE})=0.04(0.02)$ ), 111 metabolites changed in the FF2 group (47 up, 64 down; $\log _{2} \mathrm{FC}$ range $=-3.7$ to +2.4 ; mean (SE) $=-0.07(0.03)$ ). Subjecting those changes $\left(\log _{2} \mathrm{FC}\right)$ in each group that were significantly changed from baseline by paired $t$-test to one-way ANOVA showed that the magnitude of changes were different between groups (ANOVA $p=0.04$ ) and Tukey's post hoc tests demonstrated that FF2 produced a set of changes from baseline that was significantly different from both control (HSD $p=0.03$ ) but not FF1 (HSD $p>0.05$ ). Thus, FF2 impacted the global serum metabolome of aged cats to an extent that was different from control. The SPLS indicated that there were differences between the groups' changes from baseline (Figure 1), with a greater separation between control and both FF1 and FF2 than between FF1 and FF2. Component 1 of the SPLS loadings segregated control from FF1 and FF2, whereas component 2 segregated control and FF1 from FF2 (Table S2). Revealingly, SPLS component 1 contained metabolites associated with glutathione metabolism, methylation capacity, and microbial postbiotic production. Random Forest analysis provided discrimination between the dietary groups with an overall out of bounds class error of $4.6 \%$, where $14 / 15$ cats were correctly assigned to the control group with one cat misclassified as belonging to the FF1 group (class error 6.7\%), 14/15 cats were correctly assigned to the FF1 group with one misclassified into the FF2 group (class error 6.7\%), and all cats (14/14) correctly classified in the FF2 group. Here too, metabolites associated with methylation capacity and microbial postbiotic production were featured, although glutathione metabolism was not featured as prominently (Table S3). Based on the global metabolome ANOVA, SPLS, and Random Forest results, metabolite classes associated with glutathione metabolism, methylation, and microbial postbiotic production were selected for further analysis.

As a multivariate class, changes from baseline of glutathione-related metabolites were significantly altered by food consumption (MANOVA $p \leq 0.001$; Table S1). Concentrations of glutathione and its metabolites were evaluated after feeding RPF for three months (Table 6). The oxidized metabolites glutathione disulfide (GSSG) and cystine-glutathione disulfide were decreased from baseline $(p<0.05)$ in cats fed FF1 and FF2, whereas there was no significant change in cats fed control food. The glutathione biosynthesis pathway-related metabolite ophthalmate decreased in cats fed FF1 and FF2, whereas there was no significant change in cats fed control food. On the other hand, concentrations of homocysteine increased in cats fed FF1 and FF2, whereas there was no significant change in cats fed control food. 
Scores Plot

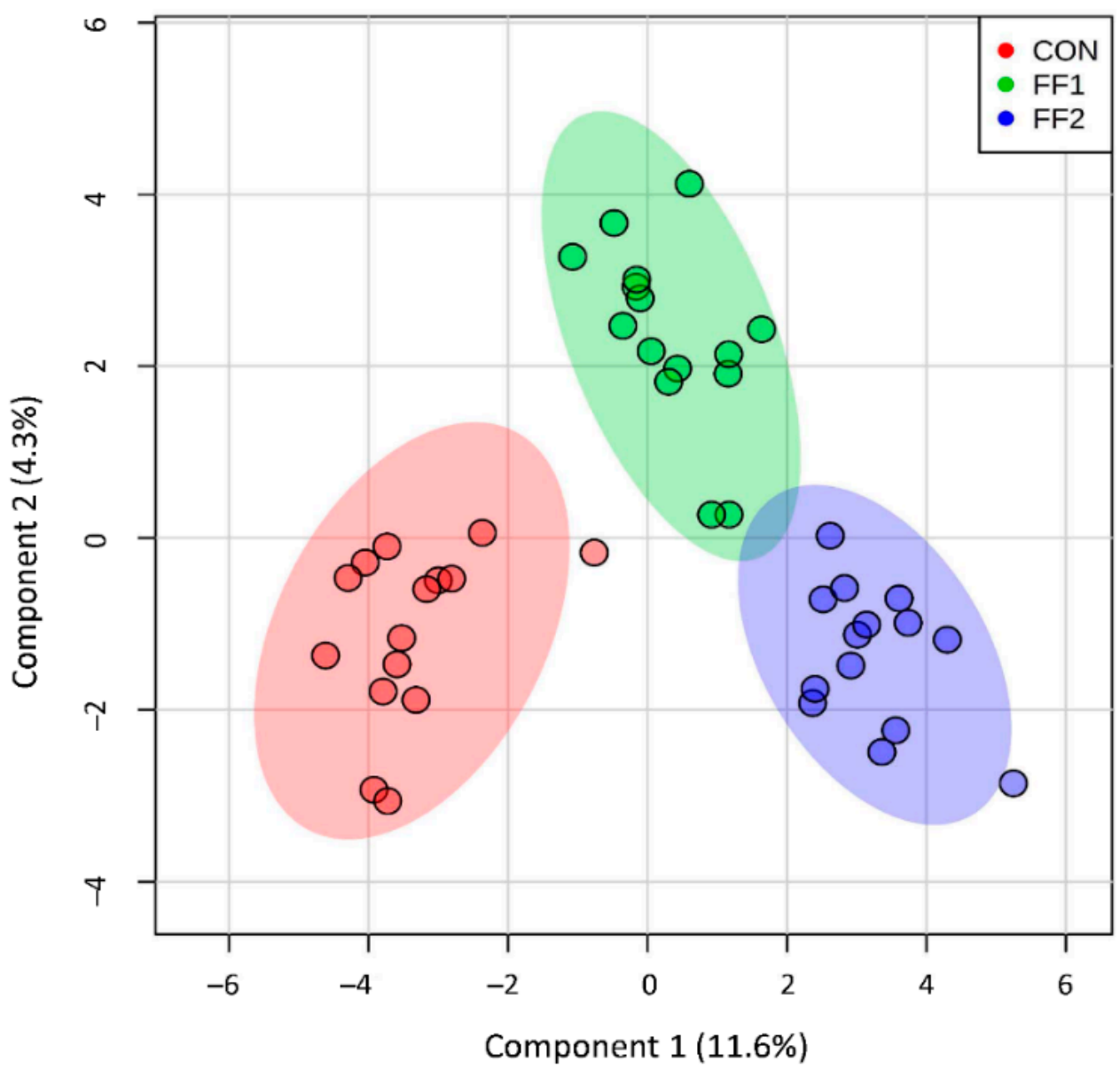

Figure 1. Metabolomic analysis was performed on serum samples taken at baseline and after three months of consuming control food (CON), or one of two functional foods (FF1 and FF2). The sparse partial least squares analysis (SPLS) was used to distinguish between different renal protective food (RPF) groups, and indicated that there were differences between the groups' changes from baseline, with a greater separation between cats consuming control food and both functional foods (FF1 and FF2) than between FF1 and FF2 
Table 6. Effect of feeding control ${ }^{1}$ or one of two functional foods (FF1 and FF2) ${ }^{2}$ on plasma concentrations of antioxidants, methylation substrates, and compounds produced by gut microbial metabolism in cats at baseline (T0) and after a three month (T3) feeding period ${ }^{3}$.

\begin{tabular}{|c|c|c|c|c|c|c|c|c|c|c|c|c|c|c|}
\hline \multirow{3}{*}{ Metabolite Class $^{4}$} & \multirow{2}{*}{\multicolumn{3}{|c|}{$\begin{array}{c}\text { Control } \\
\text { T3 - T0 DELTA }\end{array}$}} & \multirow{2}{*}{\multicolumn{3}{|c|}{\begin{tabular}{|c|} 
Functional Food 1 \\
T3 - T0 DELTA
\end{tabular}}} & \multirow{2}{*}{\multicolumn{3}{|c|}{$\begin{array}{c}\text { Functional Food } 2 \\
\text { T3 - T0 DELTA }\end{array}$}} & \multicolumn{5}{|c|}{ One Way-ANOVA on T3 - T0 } \\
\hline & & & & & & & & & & \multirow[b]{2}{*}{$p$-Value } & \multirow[b]{2}{*}{$q$-Value } & \multicolumn{3}{|c|}{ Tukey's HSD ${ }^{6}$ Post Hoc } \\
\hline & Mean & SEM $^{5}$ & $\begin{array}{c}\text { Paired } \\
t \text {-Test } \\
p \text {-Value }\end{array}$ & Mean & SEM $^{5}$ & $\begin{array}{c}\text { Paired } \\
t \text {-Test } \\
p \text {-Value }\end{array}$ & Mean & SEM $^{5}$ & $\begin{array}{c}\text { Paired } \\
t \text {-Test } \\
p \text {-Value }\end{array}$ & & & $\begin{array}{l}\text { Control vs. } \\
\text { FF1 }\end{array}$ & $\begin{array}{c}\text { Control vs. } \\
\text { FF2 }\end{array}$ & $\begin{array}{l}\text { FF1 vs. } \\
\text { FF2 }\end{array}$ \\
\hline \multicolumn{15}{|l|}{ Glutathione: } \\
\hline ophthalmate & 0.15 & 0.19 & 0.39 & -0.43 & 0.26 & 0.07 & -1.59 & 0.44 & $6.3 \times 10^{-5}$ & $9.0 \times 10^{-5}$ & $2.5 \times 10^{-4}$ & 0.12 & $5.5 \times 10^{-5}$ & 0.02 \\
\hline pyroglutamine & 0.23 & 0.18 & 0.12 & -1.80 & 1.08 & $4.6 \times 10^{-3}$ & -1.61 & 0.91 & 0.01 & $2.7 \times 10^{-3}$ & $3.9 \times 10^{-3}$ & 0.01 & 0.01 & 0.98 \\
\hline glutathione, oxidized (GSSG) & -0.10 & 0.15 & 0.69 & -0.41 & 0.11 & $4.5 \times 10^{-4}$ & -0.55 & 0.10 & $9.6 \times 10^{-6}$ & $7.3 \times 10^{-4}$ & $1.5 \times 10^{-3}$ & 0.03 & 0.00 & 0.28 \\
\hline cysteine-glutathione disulfide & -0.03 & 0.07 & 0.65 & -0.12 & 0.08 & 0.03 & -0.22 & 0.04 & $2.3 \times 10^{-5}$ & 0.01 & 0.01 & 0.42 & $4.7 \times 10^{-3}$ & 0.10 \\
\hline homocysteine & -0.14 & 0.17 & 0.36 & 0.40 & 0.15 & 0.01 & 0.31 & 0.20 & 0.31 & 0.05 & 0.04 & 0.04 & 0.31 & 0.59 \\
\hline \multicolumn{15}{|l|}{ Methylation: } \\
\hline glycine & -0.16 & 0.07 & 0.01 & -0.12 & 0.10 & 0.32 & -0.21 & 0.08 & 0.10 & 0.21 & 0.10 & 0.95 & 0.35 & 0.22 \\
\hline sarcosine (N-methylglycine) & -0.03 & 0.14 & 0.85 & 0.21 & 0.10 & 0.09 & 0.19 & 0.18 & 0.80 & 0.47 & 0.15 & 0.49 & 0.98 & 0.60 \\
\hline betaine & 1.09 & 0.25 & $1.1 \times 10^{-6}$ & -0.32 & 0.08 & $7.0 \times 10^{-5}$ & -0.02 & 0.09 & 0.95 & $1.9 \times 10^{-10}$ & $4.5 \times 10^{-9}$ & $3.5 \times 10^{-10}$ & $4.6 \times 10^{-6}$ & 0.01 \\
\hline 5-methylcytidine & -0.03 & 0.06 & 0.57 & 0.95 & 0.27 & $1.3 \times 10^{-3}$ & 4.99 & 0.49 & $1.4 \times 10^{-12}$ & $2.1 \times 10^{-14}$ & $7.6 \times 10^{-13}$ & $2.3 \times 10^{-4}$ & $2.3 \times 10^{-10}$ & $4.2 \times 10^{-9}$ \\
\hline 5-methylcytosine & -0.05 & 0.09 & 0.51 & 0.37 & 0.14 & 0.03 & 2.05 & 0.33 & $4.7 \times 10^{-5}$ & $1.4 \times 10^{-5}$ & $4.4 \times 10^{-5}$ & 0.11 & $8.4 \times 10^{-6}$ & $4.5 \times 10^{-3}$ \\
\hline 5-hydroxymethylcytosine & -0.08 & 0.06 & 0.19 & 0.32 & 0.08 & $3.4 \times 10^{-3}$ & 0.66 & 0.12 & $1.1 \times 10^{-3}$ & $1.8 \times 10^{-4}$ & $4.4 \times 10^{-4}$ & 0.02 & $1.3 \times 10^{-4}$ & 0.20 \\
\hline 5-methyl-2'-deoxycytidine & -0.09 & 0.07 & 0.03 & 0.19 & 0.08 & 0.03 & 0.35 & 0.12 & 0.01 & $2.1 \times 10^{-3}$ & $3.4 \times 10^{-3}$ & 0.06 & $1.6 \times 10^{-3}$ & 0.35 \\
\hline \multicolumn{15}{|l|}{ Putrefactive Postbiotics: } \\
\hline 3-indoxyl sulfate & -0.36 & 0.15 & 0.03 & -0.84 & 0.24 & 0.01 & -1.16 & 0.18 & $9.5 \times 10^{-5}$ & 0.01 & 0.01 & 0.42 & 0.01 & 0.16 \\
\hline 2-oxindole-3-acetate & -0.02 & 0.15 & 0.87 & -0.24 & 0.16 & 0.25 & -1.04 & 0.18 & $3.5 \times 10^{-6}$ & $4.8 \times 10^{-5}$ & $1.4 \times 10^{-4}$ & 0.58 & $6.0 \times 10^{-5}$ & $1.2 \times 10^{-3}$ \\
\hline indolepropionate & -0.25 & 0.19 & 0.15 & 0.78 & 0.57 & 0.21 & 0.12 & 0.43 & 0.27 & 0.11 & 0.06 & 0.29 & 0.83 & 0.11 \\
\hline indoleacrylate & 0.02 & 0.20 & 0.86 & 0.45 & 0.27 & 0.08 & 0.24 & 0.31 & 0.66 & 0.58 & 0.17 & 0.56 & 0.95 & 0.76 \\
\hline indolelactate & -0.14 & 0.11 & 0.09 & 0.07 & 0.17 & 0.95 & 0.07 & 0.11 & 0.97 & 0.52 & 0.16 & 0.56 & 0.62 & 1.00 \\
\hline indoleacetate & 0.38 & 0.22 & 0.11 & 0.37 & 0.25 & 0.32 & -0.58 & 0.57 & 0.28 & 0.14 & 0.07 & 1.00 & 0.20 & 0.19 \\
\hline 3-(4-hydroxyphenyl)lactate (HPLA) & 0.01 & 0.07 & 0.64 & -0.19 & 0.06 & $2.6 \times 10^{-3}$ & -0.41 & 0.07 & $1.3 \times 10^{-8}$ & $4.5 \times 10^{-8}$ & $6.4 \times 10^{-7}$ & 0.01 & $2.2 \times 10^{-8}$ & $8.0 \times 10^{-4}$ \\
\hline phenylpropionylglycine & -0.71 & 0.18 & $1.2 \times 10^{-4}$ & -0.66 & 0.24 & $2.8 \times 10^{-4}$ & -1.11 & 0.28 & $9.7 \times 10^{-7}$ & 0.01 & 0.01 & 1.00 & 0.01 & 0.02 \\
\hline $\begin{array}{l}\text { 3-phenylpropionate } \\
\text { (hydrocinnamate) }\end{array}$ & -0.88 & 0.36 & 0.02 & -1.18 & 0.47 & $1.3 \times 10^{-3}$ & -2.57 & 0.79 & $1.0 \times 10^{-7}$ & $1.5 \times 10^{-4}$ & $3.8 \times 10^{-4}$ & 0.67 & $2.0 \times 10^{-4}$ & $2.4 \times 10^{-3}$ \\
\hline catechol sulfate & -0.26 & 0.29 & 0.45 & 0.05 & 0.42 & 0.87 & 0.80 & 0.31 & 0.06 & 0.31 & 0.12 & 0.82 & 0.28 & 0.60 \\
\hline 2-hydroxyphenylacetate & -0.12 & 0.14 & 0.38 & 0.05 & 0.12 & 0.79 & 0.16 & 0.13 & 0.36 & 0.40 & 0.14 & 0.67 & 0.37 & 0.86 \\
\hline 3-ethylphenylsulfate & -0.09 & 0.28 & 0.12 & -0.26 & 0.20 & 0.07 & -0.43 & 0.14 & 0.01 & 0.27 & 0.12 & 1.00 & 0.32 & 0.36 \\
\hline
\end{tabular}


Table 6. Cont.

\begin{tabular}{|c|c|c|c|c|c|c|c|c|c|c|c|c|c|c|}
\hline \multirow{3}{*}{ Metabolite Class ${ }^{4}$} & \multirow{2}{*}{\multicolumn{3}{|c|}{$\begin{array}{c}\text { Control } \\
\text { T3 - T0 DELTA }\end{array}$}} & \multirow{2}{*}{\multicolumn{3}{|c|}{$\begin{array}{c}\text { Functional Food } 1 \\
\text { T3 - T0 DELTA }\end{array}$}} & \multirow{2}{*}{\multicolumn{3}{|c|}{$\begin{array}{c}\text { Functional Food } 2 \\
\text { T3 - T0 DELTA }\end{array}$}} & \multicolumn{5}{|c|}{ One Way-ANOVA on T3 - T0 } \\
\hline & & & & & & & & & & \multirow[b]{2}{*}{$p$-Value } & \multirow[b]{2}{*}{$q$-Value } & \multicolumn{3}{|c|}{ Tukey's HSD ${ }^{6}$ Post Hoc } \\
\hline & Mean & SEM $^{5}$ & $\begin{array}{c}\text { Paired } \\
t \text {-Test } \\
p \text {-Value }\end{array}$ & Mean & SEM $^{5}$ & $\begin{array}{c}\text { Paired } \\
t \text {-Test } \\
p \text {-Value }\end{array}$ & Mean & SEM $^{5}$ & $\begin{array}{c}\text { Paired } \\
t \text {-Test } \\
p \text {-Value }\end{array}$ & & & $\begin{array}{c}\text { Control vs. } \\
\text { FF1 }\end{array}$ & $\begin{array}{c}\text { Control vs. } \\
\text { FF2 }\end{array}$ & $\begin{array}{l}\text { FF1 vs. } \\
\text { FF2 }\end{array}$ \\
\hline p-cresol sulfate & 0.28 & 0.18 & 0.02 & 0.31 & 0.22 & 0.72 & -0.36 & 0.37 & 0.25 & 0.22 & 0.10 & 0.91 & 0.21 & 0.40 \\
\hline phenol sulfate & -0.21 & 0.22 & 0.32 & -0.03 & 0.21 & 0.98 & -0.32 & 0.17 & 0.08 & 0.58 & 0.17 & 0.72 & 0.97 & 0.59 \\
\hline 3-(4-hydroxyphenyl)propionate & 0.63 & 0.44 & 0.69 & -1.29 & 0.81 & 0.44 & -1.30 & 2.05 & 0.34 & 0.36 & 0.13 & 0.71 & 0.79 & 0.33 \\
\hline phenylacetylglutamine & 0.75 & 0.24 & $2.9 \times 10^{-3}$ & 0.23 & 0.19 & 0.09 & -0.36 & 0.66 & 0.61 & 0.32 & 0.13 & 0.57 & 0.31 & 0.88 \\
\hline phenylacetate & 0.73 & 0.33 & 0.03 & 0.07 & 0.23 & 0.56 & -1.48 & 1.04 & 0.19 & 0.05 & 0.03 & 0.70 & 0.04 & 0.21 \\
\hline phenylacetylglycine & 0.63 & 0.26 & 0.02 & 0.13 & 0.24 & 0.34 & -0.60 & 0.49 & 0.43 & 0.15 & 0.08 & 0.87 & 0.14 & 0.33 \\
\hline phenyllactate (PLA) & -0.46 & 0.27 & 0.01 & -0.20 & 0.09 & 0.03 & 0.09 & 0.18 & 0.64 & 0.08 & 0.05 & 0.90 & 0.09 & 0.19 \\
\hline
\end{tabular}

${ }^{1}$ Control food was prepared by Hill's Pet Nutrition, Inc. and was similar to the pre-trial food in protein and fat content, but had added fiber, fish oil, $\alpha$-tocopheryl acetate, and ascorbyl monophosphate. See ingredient label in Table 2. ${ }^{2}$ The two functional foods differed from control food in degree of supplementation with functional lipids, presence of botanicals (fruit and vegetables), and pea and chicken protein concentrations. See ingredient label in Table 2. ${ }^{3}$ Values are means, $n=15$ (control), $n=15$ (FF1), $n=14$ (FF2). ${ }^{4}$ For each metabolite, the median was set equal to one and all samples scaled accordingly. Values presented are group means at T3, T0 or the difference of T3 - T0. ${ }^{5} \mathrm{The}$ largest SEM of the Change T3-T0 among control and two treatment groups is shown. ${ }^{6}$ Tukey's honestly significant differences post hoc analysis. 
As a multivariate class, changes from baseline of methylation-related metabolites were significantly altered by food consumption (MANOVA $p \leq 0.001$; Table S1). Concentrations of glycine, N-methylglycine (sarcosine), and tri-methylglycine (betaine) were evaluated for stability over the three-month period while cats were fed RPF (Table 6). In general, concentrations of glycine decreased in cats fed RPF, whereas concentrations of N-methylglycine increased in cats fed FF1 and concentrations of tri-methylglycine increased in cats fed control food, but decreased in cats fed FF1 (all $p<0.05)$. There was a consistent effect of RPF on methylated pyrimidines, with significantly increased concentrations of methylated cytosine congeners noted for cats fed FF1 and FF2, but not control food (5-methylcytidine, 5-methylcytosine, 5-hydroxymethylcytosine, 5-methyl-2"-deoxycytidine) (all $p<0.05)$.

\subsection{Effect of Functional Foods on Plasma Metabolite Concentrations of Compounds Produced by Gut Microbial Metabolism after a Three-Month Feeding Period}

As a multivariate class, changes from baseline of gut microbiome-related metabolites were significantly altered by food consumption (MANOVA $p \leq 0.02$; Table S1). Concentrations of 19 circulating gastrointestinal microbial metabolites were also evaluated over the three-month period when cats were fed RPF (Table 6). After consuming RPF for three months, cats fed FF1 and FF2 exhibited altered concentrations for 10/19 microbial metabolites.

Cats had decreased concentrations for seven microbial metabolites (3-indoxyl sulfate, 2-oxindole-3-acetate, 3-(4-hydroxyphenyl) lactate, phenylpropionylglycine, 3-phenylpropionate, 3-ethylphenylsulfate, and p-cresol sulfate (FF2) (all $p<0.05)$. Cats had increased concentrations of three microbial metabolites (catechol sulfate (FF2), 2-hydroxyphenylacetate (FF2), and phenylacetylglutamine (FF1) (all $p<0.05$ ). Cats fed control RPF had decreased concentrations of 3-indoxyl sulfate, indolelactate, phenylpropionylglycine, 3-phenylpropionate, 3-ethylphenylsulfate, and phenyllactate, and increased concentrations of indoleacetate, $\mathrm{p}$-cresol sulfate, phenylacetylglutamine, phenylacetate, and phenylacetylglycine (all $p<0.05)$.

\section{Discussion}

\subsection{Effects of Age on Lean Body Percent and Renal Function}

Senior-adult cats had decreased lean body percent and increased fat body percent. We have previously shown that age is associated with decreased lean body mass in dogs [5] and cats [1]. Healthy aging in humans is also associated with loss of lean body mass [18]. Muscle quality, defined as strength-to-mass ratio, also declines with age in humans [19]. Those humans with higher total body fat mass and lower total body lean mass had an accelerated rate of decline long term in muscle quality [19]. The age-related loss of lean muscle mass and muscle quality are important risk factors for mortality $[18,20]$. In our study, age was also associated with decreased serum albumin concentrations, similar to what was previously shown in dogs [5], indicating that both skeletal muscle mass and circulating protein concentrations are affected by age in animal models. Total body mass was not different between young and old cats in our study.

There was a trend for GFR to be lower in senior-adult cats, similar to what we previously showed in dogs [5]. Advanced age is reported to be associated with lower GFR in humans [21], likely because of simultaneous chronic comorbidities or kidney damage [22]. In the absence of age-related comorbidities, there are significant changes in structure and function of the kidney, yet single nephron GFR remains constant with healthy aging [23]. In humans, there is no increased risk of mortality associated with the age-related reduction in GFR [23].

Three renal function serum biomarkers (SDMA, Cr, and BUN) were not increased with age in this study. Serum BUN concentrations were actually lower in senior-adult cats at baseline, most likely because the pre-trial food had lower percent protein compared with food consumed by young adult cats. In the dog study [5], all three biomarkers were indirectly associated with age, although their 
primary association was with GFR. The difference in GFR between senior-adult cats and young adult cats was less ( $9 \%$ decline) in this study compared with the dog study ( $28 \%$ decline). Consequently, concentrations of renal function biomarkers were not found to be associated with age in this cat study. We have previously shown that SDMA is not affected by lean body percent, in contrast to Cr and BUN, making it a more sensitive renal biomarker for detecting changes in renal function in cats [1] and dogs [5].

\subsection{Effects of Functional Foods on Lean Body Percent, Renal Function, and Serum Fatty Acids and PGE Concentrations}

Feeding FF1 and FF2 for six months increased lean body percent in senior-adult cats, increased serum total protein concentrations, and maintained serum albumin concentrations. Total body mass did not change. This contrasts to our dog study [5], whereby feeding RPF did not prevent the age-associated decline in lean body percent, although, the loss tended to be smaller in dogs fed the functional foods compared with control food. Cats fed control food for six months were significantly different from cats fed FF1 and FF2 in lean body percent (smaller increase), serum total protein (decreased rather than increased) and albumin concentrations (decreased). In humans with CKD, no reliable interventions exist to prevent the age-associated loss of lean body percent [3]. Likewise, no pharmacological treatments exist to halt the progression of sarcopenia in humans [24]. In humans, the combination of nutritional interventions and physical exercise are the most effective strategies presently available for the management of sarcopenia [24,25]. Although not evaluated, it is possible that cats eating FF1 and FF2 had increased physical activity, which could explain their increase in lean body percent. Additional studies to monitor physical activity are planned.

Feeding all three foods increased GFR in senior-adult cats, although, cats fed FF1 and FF2 had greater increases than cats fed control food. The GFR in senior-adult cats were not significantly different compared with young adult cats after feeding RPF for six months. In addition, concentrations of the renal function serum biomarkers, SDMA and $\mathrm{Cr}$, were significantly lower in senior-adult cats compared with young adult cats after feeding RPF for six months.

Both functional foods contained greater amounts of fish oil ( $5 \times$ more) compared with control food, and greater amounts of wet meat chicken (control food contained chicken meal only). Both FF1 (1.9\%) and FF2 (4.0\%) contained increased amounts of fruit and vegetables compared with control food $(0 \%)$. FF1 had added pea protein to replace other carbohydrate and protein sources in control food, but contained corn gluten meal at similar concentrations compared with control food. FF2 contained no corn gluten meal and twice as much pea protein as FF1. Although macronutrient concentrations were not identical among control, FF1, and FF2 foods in this study (protein, $31.5 \%+1.3 \%$; fat, $17.4 \%+3.4 \%$; and calories, $3858+160 \mathrm{kcal}$ ), these minor differences seem less likely to explain the observed effects compared with the major changes in ingredients and bioactives noted above.

It has been reported in humans consuming foods rich in fruit and vegetables that CKD complications were reduced by increasing dietary alkali, thereby reducing acid production [26]. Foods that increase systemic inflammation have been shown to reduce kidney function in elderly humans [27]. In our study, feeding RPF for six months significantly decreased serum $\mathrm{PGE}_{2}$ concentrations from baseline in cats fed control food and FF1 (decrease was not significant for FF2). Thus, we also conclude that inflammation can be reduced by dietary ingredients and is associated with improved kidney function.

All RPF contained added mitochondrial cofactors and antioxidants (L-carnitine, ascorbic acid, and vitamin E). The mitochondrial co-factor L-carnitine has been shown to have significant health effects (improved nitrogen balance, inhibition of apoptosis, improved mitochondrial function, and antioxidant and anti-inflammatory effects) [28]. The function of L-carnitine is to transport long-chain FA from the cytosol to the mitochondria for $\beta$-oxidation. The concentration of L-carnitine decreases with age in rats $[29,30]$. Carnitine availability is usually not a limiting step in FA utilization. However, increased carnitine concentrations may have benefits (sparing of glucose and amino acid concentrations, 
preserving muscle glycogen content, and maximizing rates of oxidative ATP production) [31]. Others have shown that dietary L-carnitine decreases markers of oxidative stress and inflammation in patients with chronic diseases such as CKD (reviewed in Reference [28]). We have previous shown that serum concentrations of L-carnitine and fatty acyl carnitines are decreased in geriatric dogs. In addition, feeding dogs L-carnitine lessened the age-associated decline in circulating carnitine concentrations [10].

Patients with CKD have decreased plasma vitamin C and E concentrations [32-34]. Oral supplementation of vitamins $C$ and $E$, in combination [35,36], or as a micronutrient cocktail containing physiologic doses of antioxidant vitamins and trace minerals [36], can decrease oxidative stress in humans. The majority of studies investigating anti-oxidant treatments in CKD patients show a reduction in oxidative stress and many show improved renal function (reviewed in References [37,38]). Therefore, foods may affect kidney function by altering the balance between antioxidants and oxidizing species.

Cats fed FF1 and FF2 also had greater increases in serum concentrations of EPA and DHA, and had smaller $(n-6):(n-3)$ PUFA ratios compared with cats fed control food for six months. Dietary EPA and DHA have been shown to have a number of physiological effects in many different cell types (on the physical nature of cell membranes and membrane protein-mediated responses, on lipid mediator generation, on cell signaling, and on gene expression) [39]. EPA, DHA, and derived lysophospholipids and eicosanoids may also protect against excessive inflammatory reactions [40]. Previously reported studies in dogs, using a remnant kidney design as a model of CKD, showed independent and additive protective effects of antioxidant therapy and $(n-3)$ PUFA supplementation [41]. The rate of decline of GFR in those studies was slowed by feeding $(n-3)$ PUFA and by adding dietary antioxidants [41]. This was likely due to reduced renal oxidant injury [41].

The different protein sources among RPF may not have influenced the change in lean body mass as all foods had highly bioavailable amino acid compositions regardless of protein source. Although this study did not evaluate protein quality, studies in humans on protein quality and relation between mealtime distribution of protein intake and lean muscle loss with aging showed that lean muscle declined over two years, yet men and women with evenly distributed protein intakes and men with high protein intakes showed higher lean mass throughout the entire follow-up period [42]. However, studies of protein intake and muscle mass loss in older adults have been inconsistent, reporting both negative and positive associations (reviewed in Reference [42]).

\subsection{Effects of Functional Foods on Selected Plasma Metabolite Concentrations}

Consumption of FF1 and FF2 decreased circulating concentrations of glutathione disulfides, which are indices of oxidative stress [43]. Additionally, concentrations of ophthalmate, produced when cellular concentrations of the glutathione precursor amino acid cysteine are insufficient to keep up with biosynthetic demand [44], decreased with consumption of RPF. Ophthalmate is an inactive form of glutathione that lacks the redox active sulfur moiety. In contrast to these changes that indicate a more reduced redox state, concentrations of circulating homocysteine, a marker of oxidative stress, were increased after feeding RPF. That the change in homocysteine with feeding RPF may be more driven by methylation status rather than oxidative balance is indicated by the observation that single carbon metabolism was altered by feeding RPF. Whereas permethylated betaine was decreased, singly-methylated sarcosine was increased by feeding FF2. Concurrently, feeding both FF1 and FF2 had a uniform effect to increase methylated cytosine/cytidine. Together with the increase in homocysteine, the results could indicate that methyl groups were reapportioned from betaine to cytosine at the expense of homocysteine remethylation. However, this had no significant effect on circulating methionine concentrations (no change in serum methionine concentrations for FF1 or FF2, data not shown). It would be interesting to examine the impact on specific epigenetic markers of renal health in cats fed RPF, given the consistent effects on methylated cytosine [45]. Additionally, bolstering the dietary single carbon supply may ensure a steady supply of methyl equivalents for both redox and epigenetic purposes [46]. 
The concentrations of nearly $50 \%$ of microbial postbiotics detected in the metabolomics screen were changed with FF1 and/or FF2 feeding, and more than two-thirds of those that changed decreased. Uremic toxins are mainly derived from dietary metabolites, and may result from kidney failure as well as promote the progression of CKD (reviewed in Reference [47]). There is current interest in decreasing gut microbial production of uremic toxins, although this goal must be balanced with the preservation of production of beneficial postbiotics. Consumption of both RPF, and the control food, decreased circulating concentrations of the uremic toxin 3-indoxyl sulfate [48], and furthermore, cats fed FF2 had a significantly greater decrease from baseline in 3-indoxyl sulfate concentrations compared with cats fed control food. Indoxyl sulfate is metabolized by the liver from indole and associated metabolites, which are produced in the intestine from tryptophan by the microbiota. It is normally excreted from healthy kidneys by the organic anion transporter 3, but it accumulates as CKD progresses and induces tubulointerstitial fibrosis and glomerular sclerosis (reviewed in Reference [47]). Therapeutic strategies in humans for lowering indoxyl sulfate serum concentrations also include dietary protein restriction, enhanced dietary fiber and antioxidants [49]. In contrast, concentrations of catechol sulfate, a postbiotic that can be derived from dietary polyphenols [50], were significantly increased by feeding FF2. The only other postbiotics that increased with feeding FF1 and FF2 were postbiotics derived from polyphenols or phenyl amino acids derived by microbial metabolism (2-hydroxyphenylacetate, phenylacetylglutamine) [51]. Altogether, RPF appeared to produce an overall dampening of the concentrations of microbial postbiotics, with a few exceptions that may indicate continued microbial metabolism of dietary polyphenols.

\section{Conclusions}

Dietary supplementation of a control maintenance food with different protein sources, increasing concentrations of botanicals (fruit and vegetables), antioxidants (vitamins $\mathrm{C}$ and $\mathrm{E}$ ) and L-carnitine, and increased amounts of functional lipids (fish oil) and feeding to healthy senior-adult cats for six months, increased lean-body percent, maintained serum albumin concentrations, increased GFR, and decreased serum SDMA concentrations. Plasma metabolite concentrations were consistent with less oxidative stress and a reapportioning of methyl groups from betaine to cytosine. In addition, consumption of RPF altered concentrations of microbial postbiotics, including decreasing the plasma concentration of the uremic toxin 3-indoxyl sulfate. These changes may aid in offsetting sarcopenia and the chronic inflammation associated with aging in cats. Future studies are warranted to confirm the potential health benefits and anti-aging effects in client-owned senior-adult cats.

Supplementary Materials: The following are available online at http://www.mdpi.com/2218-1989/9/10/238/s1, Table S1: Determination of whether the change from baseline for a metabolite class (glutathione pathway, methylation or microbial postbiotics) differed across the study groups was performed by multivariate analysis of variance (MANOVA) using the Identity Function, which fits a model for each metabolite individually and then jointly tests the models together. Shown here are the separate MANOVA $p$ values for Wilks' lambda, Pillai's trace, Hotelling-Lawley, and Roy's max root; Table S2: The sparse partial least squares analysis (SPLS) indicated that there were differences between the groups' changes from baseline, with a greater separation between control and both FF1 and FF2 than between FF1 and FF2. Component 1 of the SPLS loadings segregated control from FF1, whereas component 2 segregated control and FF1 from FF2. Revealingly, SPLS component 1 contained metabolites associated with glutathione metabolism, methylation capacity, and microbial postbiotic production; Table S3: Random Forest analysis provided discrimination between the dietary groups with an overall out of bounds class error of $4.6 \%$, where $14 / 15$ cats were correctly assigned to the control group with one cat misclassified as belonging to the FF1 group (class error 6.7\%), 14/15 cats were correctly assigned to the FF1 group with one misclassified into the FF2 group (class error 6.7\%), and all cats (14/14) correctly classified in the FF2 group. Metabolites associated with methylation capacity and microbial postbiotic production were featured, although glutathione metabolism was not featured as prominently.

Author Contributions: Conceptualization, J.A.H., M.I.J., D.E.J.; methodology, M.I.J., G.F., M.Y., D.E.J.; formal analysis, J.A.H., M.I.J., D.E.J.; resources, D.E.J.; data curation, D.E.J.; writing-original draft preparation, J.A.H.; writing-review and editing, J.A.H., M.I.J., D.E.J.; project administration, D.E.J.; funding acquisition, D.E.J.

Funding: This research was funded by Hill's Pet Nutrition, Inc., Topeka, Kansas, USA (http://www/hillpet.com/ our-company.html). 
Conflicts of Interest: Although the funder (Hill's Pet Nutrition, Inc.) provided support in the form of salaries for two of the authors (M.I.J., D.E.J.), the funding decision makers had no role in the design of the study; in the collection, analyses, or interpretation of data; in the writing of the manuscript, or in the decision to publish the results. The research was performed at the Pet Nutrition Center, Topeka, Kansas, where these authors work. Two of the authors (G.F., M.Y.) have an affiliation to a commercial company, as employees of IDEXX Laboratories, Inc., that holds a patent on the ELISA methodology for measuring SDMA concentration (http://www.idexx.com/view/xhtml/en_us/corporate/home.jsf). United States Patent No. US 481,690 B2; July 9, 2013; Murthy et al., Methods for Detecting Symmetrical Dimethylarginine. This does not alter our adherence to Metabolites policies on sharing data and materials.

\section{References}

1. Hall, J.A.; Yerramilli, M.; Obare, E.; Yerramilli, M.; Yu, S.; Jewell, D.E. Comparison of serum concentrations of symmetric dimethylarginine and creatinine as kidney function biomarkers in healthy geriatric cats fed reduced protein foods enriched with fish oil, L-carnitine, and medium-chain triglycerides. Vet. J. 2014, 202, 588-596. [CrossRef] [PubMed]

2. Hall, J.A.; Yerramilli, M.; Obare, E.; Yerramilli, M.; Jewell, D.E. Comparison of serum concentrations of symmetric dimethylarginine and creatinine as kidney function biomarkers in cats with chronic kidney disease. J. Vet. Intern. Med. 2014, 28, 1676-1683. [CrossRef] [PubMed]

3. Wang, X.H.; Mitch, W.E. Mechanisms of muscle wasting in chronic kidney disease. Nat. Rev. Nephrol. 2014, 10, 504-516. [CrossRef] [PubMed]

4. Vlassara, H.; Torreggiani, M.; Post, J.B.; Zheng, F.; Uribarri, J.; Striker, G.E. Role of oxidants/inflammation in declining renal function in chronic kidney disease and normal aging. Kidney Int. Suppl. 2009, 114, S3-S11. [CrossRef] [PubMed]

5. Hall, J.A.; Yerramilli, M.; Obare, E.; Panickar, K.S.; Bobe, G.; Jewell, D.E. Nutritional interventions that slow the age-associated decline in renal function in a canine geriatric model for elderly humans. J. Nutr. Health Aging 2016, 20, 1010-1023. [CrossRef]

6. Bauer, J.; Biolo, G.; Cederholm, T.; Cesari, M.; Cruz-Jentoft, A.J.; Morley, J.E.; Phillips, S.; Sieber, C.; Stehle, P.; Teta, D.; et al. Evidence-based recommendations for optimal dietary protein intake in older people: A position paper from the prot-age study group. J. Am. Med. Dir. Assoc. 2013, 14, 542-559. [CrossRef]

7. Polzin, D.J. Evidence-based step-wise approach to managing chronic kidney disease in dogs and cats. J. Vet. Emerg. Crit. Care (San Antonio) 2013, 23, 205-215. [CrossRef]

8. Forrester, S.; Adams, L.; Allen, T. Chronic kidney disease. In Small Animal Clinical Nutrition, 5th ed.; Hand, M., Thatcher, C., Remillard, R., Roudebush, P., Novotny, B., Eds.; Mark Morris Institute: Topeka, KS, USA, 2010; pp. 765-810.

9. Bartges, J.W. Chronic kidney disease in dogs and cats. Vet. Clin. N. Am. Small Anim. Pract. 2012, 42, 669-692. [CrossRef]

10. Hall, J.A.; Jewell, D.E. Feeding healthy beagles medium-chain triglycerides, fish oil, and carnitine offsets age-related changes in serum fatty acids and carnitine metabolites. PLoS ONE 2012, 7, e49510. [CrossRef]

11. Vogt, A.H.; Rodan, I.; Brown, M.; Brown, S.; Buffington, C.A.; Forman, M.J.; Neilson, J.; Sparkes, A.; European Society of Feline Medicine; Feline Advisory Bureaus Well Cat for Life. AAFP-AAHA: Feline life stage guidelines. J. Am. Anim. Hosp. Assoc. 2010, 46, 70-85. [CrossRef]

12. NRC. Guide for the Care and Use of Laboratory Animals; National Academy Press: Washington, DC, USA, 2011.

13. Hall, J.A.; Melendez, L.D.; Jewell, D.E. Using gross energy improves metabolizable energy predictive equations for pet foods whereas undigested protein and fiber content predict stool quality. PLOS ONE 2013, 8, e54405. [CrossRef] [PubMed]

14. Roush, J.K.; Dodd, C.E.; Fritsch, D.A.; Allen, T.A.; Jewell, D.E.; Schoenherr, W.D.; Richardson, D.C.; Leventhal, P.S.; Hahn, K.A. Multicenter veterinary practice assessment of the effects of omega-3 fatty acids on osteoarthritis in dogs. J. Am. Vet. Med. Assoc. 2010, 236, 59-66. [CrossRef] [PubMed]

15. Folch, J.; Lees, M.; Sloane Stanley, G.H. A simple method for the isolation and purification of total lipides from animal tissues. J. Biol. Chem. 1957, 226, 497-509. [PubMed]

16. De Baere, S.; Smets, P.; Finch, N.; Heiene, R.; De Backer, P.; Daminet, S.; Croubels, S. Quantitative determination of exo- and endo-iohexol in canine and feline samples using high performance liquid chromatography with ultraviolet detection. J. Pharm. Biomed. Anal. 2012, 61, 50-56. [CrossRef] [PubMed] 
17. Chong, J.; Soufan, O.; Li, C.; Caraus, I.; Li, S.; Bourque, G.; Wishart, D.S.; Xia, J. Metaboanalyst 4.0: Towards more transparent and integrative metabolomics analysis. Nucleic Acids Res. 2018, 46, W486-W494. [CrossRef] [PubMed]

18. Santanasto, A.J.; Goodpaster, B.H.; Kritchevsky, S.B.; Miljkovic, I.; Satterfield, S.; Schwartz, A.V.; Cummings, S.R.; Boudreau, R.M.; Harris, T.B.; Newman, A.B. Body composition remodeling and mortality: The health aging and body composition study. J. Gerontol. Ser. A Biol. Sci. Med. Sci. 2017, 72, 513-519. [CrossRef] [PubMed]

19. Fabbri, E.; Chiles Shaffer, N.; Gonzalez-Freire, M.; Shardell, M.D.; Zoli, M.; Studenski, S.A.; Ferrucci, L. Early body composition, but not body mass, is associated with future accelerated decline in muscle quality. J. Cachexia Sarcopenia Muscle 2017, 8, 490-499. [CrossRef]

20. Rantanen, T.; Harris, T.; Leveille, S.G.; Visser, M.; Foley, D.; Masaki, K.; Guralnik, J.M. Muscle strength and body mass index as long-term predictors of mortality in initially healthy men. J. Gerontol. Ser. A Biol. Sci. Med. Sci. 2000, 55, M168-M173. [CrossRef]

21. Wang, X.L.; Vrtiska, T.J.; Avula, R.T.; Walters, L.R.; Chakkera, H.A.; Kremers, W.K.; Lerman, L.O.; Rule, A.D. Age, kidney function, and risk factors associate differently with cortical and medullary volumes of the kidney. Kidney Int. 2014, 85, 677-685. [CrossRef]

22. Abdulkader, R.; Burdmann, E.A.; Lebrao, M.L.; Duarte, Y.A.O.; Zanetta, D.M.T. Aging and decreased glomerular filtration rate: An elderly population-based study. PLoS ONE 2017, 12, e0189935. [CrossRef]

23. Hommos, M.S.; Glassock, R.J.; Rule, A.D. Structural and functional changes in human kidneys with healthy aging. J. Am. Soc. Nephrol. 2017, 28, 2838-2844. [CrossRef] [PubMed]

24. Calvani, R.; Miccheli, A.; Landi, F.; Bossola, M.; Cesari, M.; Leeuwenburgh, C.; Sieber, C.C.; Bernabei, R.; Marzetti, E. Current nutritional recommendations and novel dietary strategies to manage sarcopenia. J. Frailty Aging 2013, 2, 38-53. [PubMed]

25. Shlisky, J.; Bloom, D.E.; Beaudreault, A.R.; Tucker, K.L.; Keller, H.H.; Freund-Levi, Y.; Fielding, R.A.; Cheng, F.W.; Jensen, G.L.; Wu, D.; et al. Nutritional considerations for healthy aging and reduction in age-related chronic disease. Adv. Nutr. 2017, 8, 17-26. [CrossRef] [PubMed]

26. Jain, N.; Reilly, R.F. Effects of dietary interventions on incidence and progression of CKD. Nat. Rev. Nephrol 2014, 10, 712-724. [CrossRef] [PubMed]

27. Xu, H.; Sjogren, P.; Arnlov, J.; Banerjee, T.; Cederholm, T.; Riserus, U.; Lindholm, B.; Lind, L.; Carrero, J.J. A proinflammatory diet is associated with systemic inflammation and reduced kidney function in elderly adults. J. Nutr. 2015, 145, 729-735. [CrossRef]

28. Ringseis, R.; Keller, J.; Eder, K. Mechanisms underlying the anti-wasting effect of L-carnitine supplementation under pathologic conditions: Evidence from experimental and clinical studies. Eur. J. Nutr. 2013, 52, 1421-1442. [CrossRef]

29. Juliet, P.A.; Balasubramaniam, D.; Balasubramaniam, N.; Panneerselvam, C. Carnitine: A neuromodulator in aged rats. J. Gerontol. Ser. A Biol. Sci. Med. Sci. 2003, 58, 970-974. [CrossRef]

30. Thangasamy, T.; Subathra, M.; Sittadjody, S.; Jeyakumar, P.; Joyee, A.G.; Mendoza, E.; Chinnakkanu, P. Role of L-carnitine in the modulation of immune response in aged rats. Clin. Chim. Acta Int. J. Clin. Chem. 2008, 389, 19-24. [CrossRef]

31. Owen, L.; Sunram-Lea, S.I. Metabolic agents that enhance atp can improve cognitive functioning: A review of the evidence for glucose, oxygen, pyruvate, creatine, and L-carnitine. Nutrients 2011, 3, 735-755. [CrossRef]

32. Takahashi, N.; Morimoto, S.; Okigaki, M.; Seo, M.; Someya, K.; Morita, T.; Matsubara, H.; Sugiura, T.; Iwasaka, T. Decreased plasma level of vitamin $\mathrm{C}$ in chronic kidney disease: Comparison between diabetic and non-diabetic patients. Nephrol. Dial. Transpl. 2011, 26, 1252-1257. [CrossRef]

33. Fletcher, A.E.; Breeze, E.; Shetty, P.S. Antioxidant vitamins and mortality in older persons: Findings from the nutrition add-on study to the medical research council trial of assessment and management of older people in the community. Am. J. Clin. Nutr. 2003, 78, 999-1010. [CrossRef] [PubMed]

34. Karamouzis, I.; Sarafidis, P.A.; Karamouzis, M.; Iliadis, S.; Haidich, A.B.; Sioulis, A.; Triantos, A.; Vavatsi-Christaki, N.; Grekas, D.M. Increase in oxidative stress but not in antioxidant capacity with advancing stages of chronic kidney disease. Am. J. Nephrol. 2008, 28, 397-404. [CrossRef] [PubMed]

35. Boudouris, G.; Verginadis, I.I.; Simos, Y.V.; Zouridakis, A.; Ragos, V.; Karkabounas, S.; Evangelou, A.M. Oxidative stress in patients treated with continuous ambulatory peritoneal dialysis (CAPD) and the significant role of vitamin C and E supplementation. Int. Urol. Nephrol. 2013, 45, 1137-1144. [CrossRef] [PubMed] 
36. Moffitt, T.A.; Garrett, P.J.; Hannon-Fletcher, M.P. Micronutrient supplementation in maintenance haemodialysis patients enhances activity of antioxidant enzymes. J. Nephrol. 2013, 26, 403-411. [CrossRef] [PubMed]

37. Small, D.M.; Coombes, J.S.; Bennett, N.; Johnson, D.W.; Gobe, G.C. Oxidative stress, anti-oxidant therapies and chronic kidney disease. Nephrology (Carlton) 2012, 17, 311-321. [CrossRef]

38. Sung, C.C.; Hsu, Y.C.; Chen, C.C.; Lin, Y.F.; Wu, C.C. Oxidative stress and nucleic acid oxidation in patients with chronic kidney disease. Oxid. Med. Cell. Longev. 2013, 2013, 301982. [CrossRef]

39. Calder, P.C.; Yaqoob, P. Understanding omega-3 polyunsaturated fatty acids. Postgrad. Med. 2009, 121, 148-157. [CrossRef]

40. Hall, J.A.; Brockman, J.A.; Jewell, D.E. Dietary fish oil alters the lysophospholipid metabolomic profile and decreases urinary 11-dehydro thromboxane $\mathrm{B}(2)$ concentration in healthy beagles. Vet. Immunol. Immunopathol. 2011, 144, 355-365. [CrossRef]

41. Brown, S.A. Oxidative stress and chronic kidney disease. Vet. Clin. N. Am. Small Anim. Pract. 2008, 38, 157-166. [CrossRef]

42. Farsijani, S.; Morais, J.A.; Payette, H.; Gaudreau, P.; Shatenstein, B.; Gray-Donald, K.; Chevalier, S. Relation between mealtime distribution of protein intake and lean mass loss in free-living older adults of the nuage study. Am. J. Clin. Nutr. 2016, 104, 694-703. [CrossRef]

43. Rebrin, I.; Sohal, R.S. Pro-oxidant shift in glutathione redox state during aging. Adv. Drug Deliv. Rev. 2008, 60, 1545-1552. [CrossRef] [PubMed]

44. Dello, S.A.; Neis, E.P.; de Jong, M.C.; van Eijk, H.M.; Kicken, C.H.; Olde Damink, S.W.; Dejong, C.H. Systematic review of ophthalmate as a novel biomarker of hepatic glutathione depletion. Clin. Nutr. 2013, 32, 325-330. [CrossRef] [PubMed]

45. Reddy, M.A.; Natarajan, R. Recent developments in epigenetics of acute and chronic kidney diseases. Kidney Int. 2015, 88, 250-261. [CrossRef] [PubMed]

46. Park, L.K.; Friso, S.; Choi, S.W. Nutritional influences on epigenetics and age-related disease. Proc. Nutr. Soc. 2012, 71, 75-83. [CrossRef] [PubMed]

47. Hasegawa, S.; Jao, T.M.; Inagi, R. Dietary metabolites and chronic kidney disease. Nutrients 2017, 9, 358. [CrossRef] [PubMed]

48. Chen, C.N.; Chou, C.C.; Tsai, P.S.J.; Lee, Y.J. Plasma indoxyl sulfate concentration predicts progression of chronic kidney disease in dogs and cats. Vet. J. 2018, 232, 33-39. [CrossRef] [PubMed]

49. Nataatmadja, M.; Cho, Y.; Campbell, K.; Johnson, D.W. The roles of indoxyl sulphate and p-cresyl sulphate in patients with chronic kidney disease: A review of therapeutic options. In Chronic Kidney Disease; Rath, T., Ed.; IntechOpen: London, UK, 2018.

50. Pimpao, R.C.; Ventura, M.R.; Ferreira, R.B.; Williamson, G.; Santos, C.N. Phenolic sulfates as new and highly abundant metabolites in human plasma after ingestion of a mixed berry fruit puree. Br. J. Nutr. 2015, 113, 454-463. [CrossRef]

51. Wikoff, W.R.; Anfora, A.T.; Liu, J.; Schultz, P.G.; Lesley, S.A.; Peters, E.C.; Siuzdak, G. Metabolomics analysis reveals large effects of gut microflora on mammalian blood metabolites. Proc. Natl. Acad. Sci. USA 2009, 106, 3698-3703. [CrossRef]

(C) 2019 by the authors. Licensee MDPI, Basel, Switzerland. This article is an open access article distributed under the terms and conditions of the Creative Commons Attribution (CC BY) license (http://creativecommons.org/licenses/by/4.0/). 